\title{
多组分参与的氟烷基化反应研究进展
}

\author{
潘军吴晶晶* 吴范宏* \\ (上海应用技术大学化学与环境工程学院 上海绿色氟代制药工程技术研究中心 上海 201418)
}

\begin{abstract}
摘要 多组分参与的氟烷基化反应是当前有机氟化学研究的一个热点. 在过去的几年里, 由于新试剂新方法的不断涌 现, 多组分参与的氟烷基化反应取得了长足的进展, 不仅可以经济有效地一步将氟烷基基团与其他官能团同步引入, 而且可以将起始原料转化为多种含有生物活性或药物活性的化合物. 按照三组分二氟烷基化反应、三组分三氟甲基化 反应、三组分全氟烷基化反应、三组分单氟烷基化反应、三组分氟化反应以及四组分氟烷基化反应和总结 7 个部分, 总 结了多组分参与的氟烷基化反应在过去近十年时间里的发展进程，同时对该类反应进行了总结和展望.
\end{abstract}

关键词 多组分; 双官能团化; 二氟烷基化; 三氟甲基化; 全氟烷基化; 单氟烷基化; 氟化反应

\section{Progress in Fluoroalkylation of Multicomponent}

\author{
Pan, Jun Wu, Jingjing* Wu, Fanhong* \\ (Shanghai Engineering Research Center of Green Fluoropharmaceutical Technology, School of Chemical and Environmental \\ Engineering, Shanghai Institute of Technology, Shanghai 201418)
}

\begin{abstract}
Multi-component fluoroalkylation is a hot topic in organic fluorine chemistry. In the past few years, due to the development of new reagents and new methods, multi-component fluoroalkylation reactions have made great progress. It can not only introduce fluoroalkyl groups with other functional groups in one step economically and effectively, but also transform the starting materials into a variety of compounds with biological or pharmaceutical. The development of multi-component fluoroalkylation over the past decade is reviewed from seven parts: three-component difluoroalkylation reaction, three-component trifluoroalkylation reaction, three-component perfluoroalkylation reaction, three-component monofluoroalkylation reaction, three-component fluorination and four-component fluoroalkylation and conclusion. At the same time, this kind of reaction is summarized and prospected.

Keywords multicomponent; bifunctionalization; difluoroalkylation; trifluoromethylation; perfluoroalkylation; monofluoroalkylation; fluorination
\end{abstract}

向有机化合物分子中引入氟原子或含氟基团可以 显著改变该化合物的物理化学性质, 提升其生理性质 (如亲脂性、代谢稳定性、与靶标蛋白结合能力、细胞 膜穿透性和生物可利用度 $)^{[1]}$. 在自然界中, 天然存在的 含氟有机化合物数量极为稀少. 自 1896 年 Swarts 等 ${ }^{[2]}$ 有关一氟乙酸乙酯的合成揭开了有机氟化学的序幕以 来, 人工合成的含氟有机化合物(含氟高分子材料)被广 泛应用于医药、农药和材料科学等领域. 近年来, 随着 学术界以及工业界对含氟有机化合物的需求日益增加, 发展新的含氟有机化合物的合成方法也显得更为迫切. 含氟化合物主要是通过对有机化合物分子进行氟化或 氟烷基化得到 ${ }^{[3]}$. 氟烷基化反应主要利用各种氟烷基化
试剂通过亲核反应、亲电反应或自由基反应三种形式实 现 ${ }^{[4]}$. 在过去的几十年里, 含氟有机化合物的合成方法 取得了显著的进展, 尤其是近年来兴起的多组分参与的 氟烷基化反应发展迅速. 目前已有多篇综述对双组分氟 烷基化反应进行了分析和总结 ${ }^{[5]}$, 因此我们不再赘述. 在此, 我们重点讨论多组分参与的氟烷基化反应, 全文 涵盖了近十年来所发表的相关文献.

\section{1 三组分参与的二氟烷基化反应}

在药物以及生物活性分子的设计中常常会涉及二 氟烷基 ${ }^{[6]}$. 一方面, 二氟甲基 $\left(\mathrm{CF}_{2} \mathrm{H}\right)$ 具有很好的代谢稳 定性，常常被视作氧原子、羰基和亚甲基的生物电子等

\footnotetext{
* Corresponding authors. E-mail: wfh@sit.edu.cn; wjj@sit.edu.cn

Received July 8, 2020; revised August 9, 2020; published online September 15, 2020.

Project supported by the National Natural Science Foundation of China (Nos. 21672151, 21602136).

国家自然科学基金(Nos. 21672151, 21602136)资助项目.
} 
排体; 另一方面, 在官能化的二氟甲基(即二氟烷基 $\left.\mathrm{RCF}_{2}, \mathrm{R} \neq \mathrm{H}\right)$ 中, 二氟亚甲基的吸电子效应还会影响到 相邻官能团 $\mathrm{R}$ 的电子性质、化学性质以及反应活性. 近 年来, 三组分参与的二氟烷基化因其反应条件通常比较 温和, 反应普适性、官能团兼容性和选择性较好而受到 越来越多的关注, 为合成含有二氟烷基的化合物提供了 更多的选择空间.

\section{1 烯烃的三组分二氟烷基化反应}

烯烃类化合物由于其便宜易得的特点，常被用作有 机反应的底物, 通过双官能团化反应, 一步转化为多位 点反应产物. 可见光氧化还原催化以其成本低、易获得 和环境友好等优点, 在含氟化合物制备中得到了广泛的 应用. 2011 年, Stephenson 等 ${ }^{[7]}$ 报道了可见光催化下烯烃 与 $\mathrm{BrCF}_{2} \mathrm{CO}_{2} \mathrm{Et}$ 的双官能化反应. 在此基础上, 2016 年, Akita 等 ${ }^{[8]}$ 使用 $N$-甲苯磺酰基- $S$-二氟甲基- $S$-苯磺酰亚胺 (胡试剂)作为二氟甲基化试剂, 在光催化下, 同时将羟 基和二氟甲基引入分子中, 产物最高收率达 $88 \%$. 值得 注意的是, 该光催化体系的反应条件温和, 且具有良好 的官能团相容性, 可用于合成 $\beta-\mathrm{CF}_{2} \mathrm{H}$ 取代的醇、醚和 酯，但该反应只局限于苯乙烯类衍生物(Scheme 1).

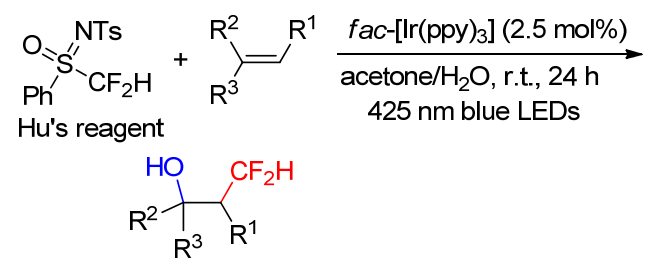

图式 1 光催化烯烃的羟基二氟甲基化反应

Scheme 1 Hydroxydifluoromethylation of styrenes using photoredox catalysis

2019 年, 舒伟等 ${ }^{[9]}$ 以 $\mathrm{BrCF}_{2} \mathrm{CO}_{2} \mathrm{Et}$ 等为二氟烷基化 试剂，在 $\mathrm{CuI} / \mathrm{Ir}(\mathrm{ppy})_{3}$ 协同催化下合成了 $\gamma$-(杂)芳基化的 羰基化合物. 该反应在室温下进行, 以 $\mathrm{Cs}_{2} \mathrm{CO}_{3}$ 为碱, 二 氯甲烷(DCM)为溶剂, 反应条件温和, $30 \mathrm{~W}$ 蓝色 LED 灯 照射 $16 \mathrm{~h}$ 就可以得到高产率的产物. 值得注意的是, 分 别使用 4,4'-二叔丁基-2,2'-二吡啶(DTBBPY)以及 4'-(4甲基苯基)-三联吡啶作为配体也能得到目标产物, 但是 收率较低. 将两者等量加入, 共同作为配体时, 可明显 提高产物收率，最高达 $88 \%$ (Scheme 2).

同年, 蔡春等 ${ }^{[10]}$ 报道了烯烃、 $\mathrm{BrCF}_{2} \mathrm{CO}_{2} \mathrm{Et}$ 以及硫醇 在 $f a c-\operatorname{Ir}(\mathrm{ppy})_{3} / \mathrm{FeCl}_{2}$ 协同催化下的烯烃硫二氟烷基化反 应. 该方法的显著优点是条件温和及无需配体, 且 C$\mathrm{S}$ 键的构筑在生物活性分子和功能材料的合成中具有重 要意义. 值得注意的是, 通过对反应机理的推测, 蔡春 等认为 $f a c-\operatorname{Ir}(\mathrm{ppy})_{3} / \mathrm{FeCl}_{2}$ 的协同催化可能对 $\mathrm{C}-\mathrm{C}$ 键和 $\mathrm{C}-\mathrm{S}$ 键的有序形成起到至关重要的作用(Scheme 3).

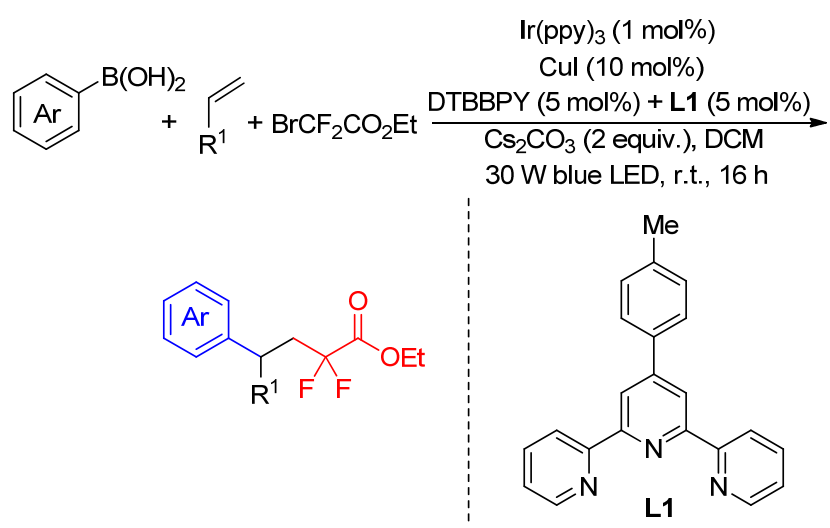

图式 2 光催化烯烃的芳基二氟烷基化反应

Scheme 2 Aryldifluoroalkylation of styrenes using photoredox catalysis

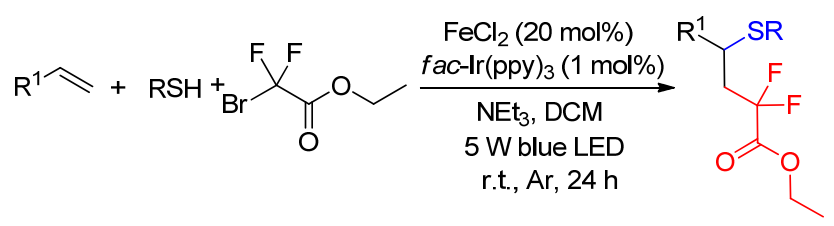

图式 3 铁催化烯烃的硫二氟烷基化反应

Scheme $3 \operatorname{Ir}(\mathrm{ppy})_{3} / \mathrm{FeCl}_{2}$ catalyzed suldifluoroalkylation of alkenes

近年来, 非活化 $\mathrm{C}\left(\mathrm{sp}^{3}\right)-\mathrm{H}$ 官能团化反应得到了研 究者的广泛关注, 其中最主要的策略是 $1, n$-氢原子转移 (HAT)过程. 然而, 通过烯烃官能团化与 $1, n$-HAT 过程 结合实现烯烃双官能化的反应报道很少. 2018 年, Nevado 等 ${ }^{[11}$ 报道了一种可见光介导的氧化还原中性条件 下未活化烯烃的 1,6-双官能团化反应. 在温和的反应条 件下，首先多种以 $\mathrm{C}$ 为中心的自由基对碳碳双键进行加 成，产生邻位自由基中间体，随后的 1,5-HAT 过程导致 远端自由基的选择性生成，该自由基可被 $\mathrm{O}$-或 $\mathrm{C}$-亲核 试剂捕获, 在室温下高效地生成新的 $\mathrm{C}\left(\mathrm{sp}^{3}\right)-\mathrm{O}$ 和 $\mathrm{C}\left(\mathrm{sp}^{3}\right)-\mathrm{C}\left(\mathrm{sp}^{2}\right)$ 键, 证明了这种光氧化还原催化是利用 光激发催化剂在温和条件下实现单电子转移(SET)反应 的有力工具(Scheme 4).

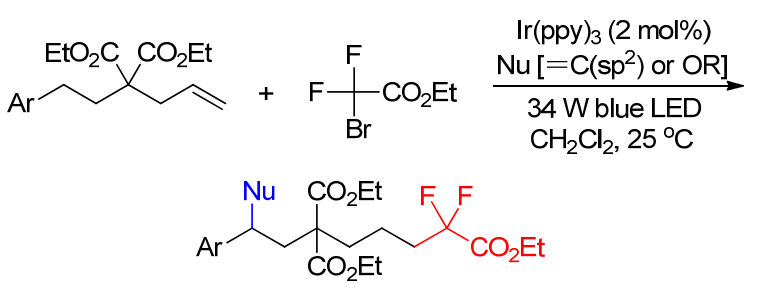

图式 4 光催化未活化烯烃的 1,6-双官能团化反应 Scheme 4 1,6-Difunctionalization of unactivated alkenes using photoredox catalysis

二氟卡宾是一种活泼的反应中间体，可以实现多种 化学反应, 如 $\mathrm{X}-\mathrm{H}$ 键 $(\mathrm{X}=\mathrm{O}, \mathrm{N}, \mathrm{S}$ 等)的插入反应等, 因 
此, 寻找高效二氟卡宾试剂及开发新颖二氟卡宾反应是 有机氟化学的一个重要研究方向. 肖吉昌课题组 ${ }^{[12]}$ 通 过对醛、酮的 Wittig 二氟烯基化反应的深入研究, 合成 出了其关键反应中间体一一二氟乙酸鏻内盐 $\left(\mathrm{Ph}_{3} \mathrm{P}^{+}\right.$$\mathrm{CF}_{2} \mathrm{CO}_{2}^{-}$, PDFA), 同时, 该课题组发现 $\mathrm{Ph}_{3} \mathrm{P}^{+} \mathrm{CF}_{2} \mathrm{CO}_{2}^{-}$ 不仅可以作为 Wittig 型二氟烯基化试剂, 也可以作为高 效的二氟卡宾试剂. 2019 年, 肖吉昌 ${ }^{[13]}$ 等利用 $\mathrm{Ph}_{3} \mathrm{P}^{+}$$\mathrm{CF}_{2} \mathrm{CO}_{2}^{-} / \mathrm{NaNH}_{2}$ (或 $\mathrm{NH}_{3}$ ) 体系实现了光催化下烯烃的氰 基二氟甲基化反应. 反应中 $\mathrm{Ph}_{3} \mathrm{P}^{+} \mathrm{CF}_{2} \mathrm{CO}_{2}^{-}$既作为二氟 卡宾试剂提供 $\mathrm{CN}^{-}$的碳源, 又可捕获质子生成二氟甲基 化试剂 $\mathrm{Ph}_{3} \mathrm{P}^{+} \mathrm{CF}_{2} \mathrm{HX}^{-}$, 从而产生 $\mathrm{CF}_{2} \mathrm{H}$ 自由基, 在温和 条件下原位生成 $\mathrm{CN}^{-}$, 避免了使用有毒氰化试剂. 该反 应具有优良的官能团相容性和广泛的底物范围, 各种芳 基烯烃均能以中等至良好的产率转化为目标产物, 克级 转化的分离收率达 $69 \%$, 显示了该反应的潜在应用价 值, 未活化烯烃也能顺利转化为预期产物, 但分子内烯 烃反应效果不好. 该方法已被成功应用于含 $\mathrm{HCF}_{2} / \mathrm{CN}$ 的雌激素酮衍生物的合成, 证明了该方法在活性分子合 成的应用潜力 (Scheme 5).

$$
\mathrm{R}^{-}+\mathrm{Ph}_{3} \mathrm{P}^{+} \mathrm{CF}_{2} \mathrm{CO}_{2}^{-}+[\mathrm{N}] \frac{\begin{array}{c}
\mathrm{DMAc} \text {, Blue LED } \\
\text { r.t., } 12 \mathrm{~h}
\end{array}}{\mathrm{Cul}(10 \mathrm{~mol} \%)}
$$

图式 5 光催化烯烃的氰基二氟甲基化

Scheme 5 Photocatalyzed cyanodifluoromethylation of alkenes

含二氟烷基的化合物的合成取得了重大进展，但几 乎都集中在通过苯乙烯母体结构构建 $\mathrm{C}-\mathrm{CF}_{2}$ 键上. 从 底物范围上讲, 通过其他杂环化合物将 $\mathrm{CF}_{2}$ 基团引入有 机分子将是一种获得二氟烷基化合物的创新性的方法, 特别是对于那些难以通过传统方法制备的化合物而言. 2016 年, 张新刚等 ${ }^{[14]}$ 报道了以富含电子的 $N$-乙烯基吡 咯烷酮作为底物, 经三组分串联反应合成含有二氟烷基 的吡咯烷酮化合物. 该反应对芳基硼酸和二氟烷基卤代 化合物都有很好的兼容性, 为药物的开发提供了一条简 便易行的途径(Scheme 6).

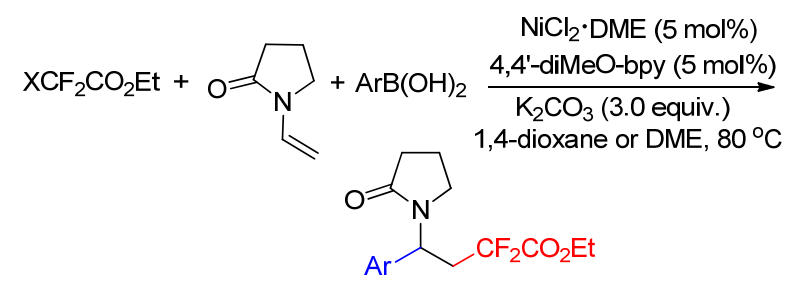

图式 6 镍催化烯烃的芳基二氟烷基化反应

Scheme 6 Ni-catalyzed aryldifluoroalkylation of alkenes

在各种过渡金属催化剂中, 镍因其价格低廉和资源 丰富，近年来在氟烷基化催化方面受到越来越多的关
注. 2019 年, 张新刚课题组 ${ }^{[15]}$ 报道了一种新的镍催化 $N$ 乙烯基-2-吡咯烷酮与二氟烷基溴和二烷基锌试剂的串 联反应，高效合成了含二氟烷基的 2-吡咯烷酮类化合 物. 该反应在温和的反应条件下进行，具有良好的官能 团耐受性，多种二氟烷基溴化物、二烷基锌试剂以及 $N$ 乙烯基啞唑烷酮和 $N$-乙烯基乙酰胺均适用于此反应. 该方该反应已被成功用于抗癫㾁药左乙拉西坦 (Levetiracetam)的结构修饰，体现了其在药物合成方面 的应用潜力 (Scheme 7).

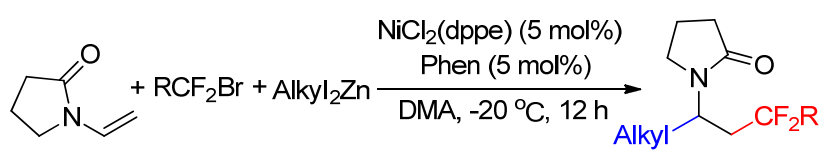

图式 7 镍催化烯烃的烷基二氟烷基化反应

Figure7 Ni-catalyzed alkyldifluoroalkylation of alkenes

随着新药开发对含氟化合物需求的日益增长，寻找 新的方法来合成含氟化合物得到了广泛关注. 丙二烯作 为一种重要的结构存在于许多天然产物中, 被广泛用作 有机合成中多种转化的重要中间体. 因此，需要发展高 效简便合成含氟丙二烯的方法, 满足含氟新药和新材料 开发的巨大需求. 2019 年, 王细胜课题组 ${ }^{[16]}$ 报道了镍催 化 1,3-烯炔的 1,4-碳氟烷基化反应，获得了结构多样的 氟烷基化丙二烯类化合物，这是含氟药物分子的重要中 间体. 该方法催化活性高，反应条件温和，底物范围广， 官能团耐受性好. 初步的机理研究表明，不同的氟烷基 卤化物可以在镍催化下原位生成不同的氟烷基自由基, 这些自由基被 1,3-烯炔捕获后通过自由基接力过程实现 1,4-碳氟烷基化(Scheme 8).

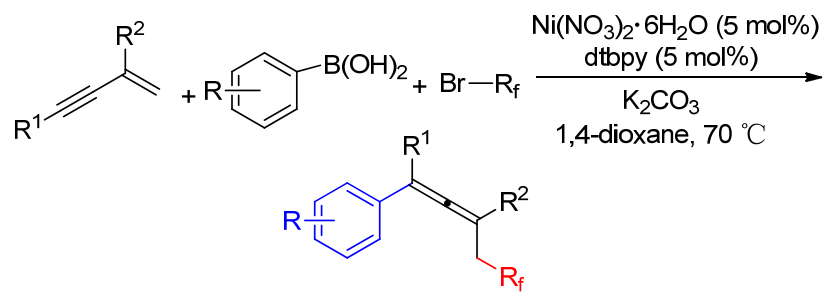

图式 8 镍催化的 1,3-烯炔的碳氟烷基化反应

Scheme 8 Ni-catalyzed carbofluoroalkylation of 1,3-enynes

在已报道的方法中, 烯烃的双官能化反应都是在氧 化还原中性条件下进行的，一个亲电试剂和一个亲核试 剂被依次引入碳碳双键中. 此外, 虽然祝介平和李金恒 等 ${ }^{[17]}$ 已成功开发了在氧化条件下允许两个不同的亲核 试剂进行烯烃的双官能团化反应，但扩大烯烃双官能团 化中官能团的引入范围，仍然是亟待解决的问题. 2018 年, 宋秋玲课题组 ${ }^{[18]}$ 在已开发的 $\mathrm{Cu} / \mathrm{B}_{2} \mathrm{pin}_{2}$ 催化体系 ${ }^{[19]}$ 的启发下，提出了铜催化的活化烯烃的硫二氟烷基化反 应. 利用 $\mathrm{B}_{2} \mathrm{pin}_{2}$ 作为有机还原剂, 溴二氟乙酸乙酯以及 
$S$ - 苯基硫代苯基砜作为两种亲电性反应物, 能使 $\mathrm{C}\left(\mathrm{sp}^{3}\right)-\mathrm{C}\left(\mathrm{F}_{2} \mathrm{R}\right)$ 键和 $\mathrm{C}\left(\mathrm{sp}^{3}\right)-\mathrm{S}(\mathrm{R})$ 键同时构建在活化烯 烃的碳碳双键上. 此反应操作简单, 底物范围广, 非对 映选择性好, 可以实现克级规模的制备, 还可以用于复 杂天然产物或天然产物类似物中双键的衍生化, 在有机 合成及药物修饰改造中具有很大的应用价值 (Scheme 9).

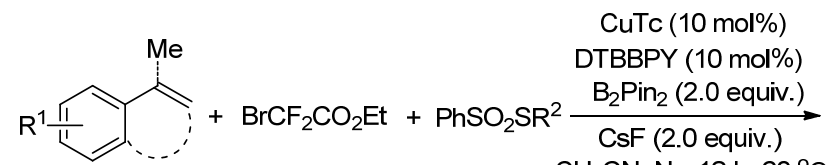
$\mathrm{CH}_{3} \mathrm{CN}, \mathrm{N}_{2}, 12 \mathrm{~h}, 60^{\circ} \mathrm{C}$<smiles>[R17]C1CCc2cc[R1]cc2C1(C)[R7]C(=O)OCC</smiles>

$( \pm)$

图式 9 铜催化活化烯烃的硫二氟烷基化反应

Scheme 9 Cu-catalyzed suldifluoroalkylation of actived alkenes

2019 年, 李志平等 ${ }^{[20]}$ 以二氟卤代物为二氟烷基化 试剂，实现了钴催化下的烯烃的过氧化二氟烷基化反 应, 这是一种新型的烯烃自由基双官能化反应. 该方法 适用范围广, 产率高, 反应条件温和, 室温下即可反应 (Scheme 10).

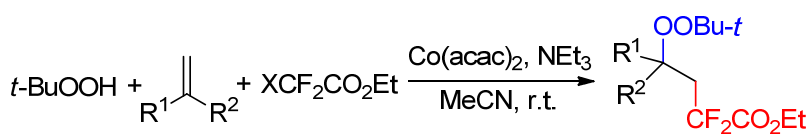

图式 10 钴催化烯烃的过氧化二氟烷基化反应 Scheme 10 Co-catalyzed peroxidedifluoroalkylation of alkenes

\section{2 炔烃的三组分二氟烷基化反应}

2015 年, 梁永民等 ${ }^{[21]}$ 通过一锅法实现了钯催化的 炔烃与碘二氟乙酸乙酯、芳基硼酸的高度区域选择性的 芳基二氟烷基化反应. 该反应不仅可以快速合成二氟烷 基化烯丙基产物, 且对炔烃以及芳基硼酸都有很好的官 能团兼容性, 同时催化剂 $\mathrm{Pd}\left(\mathrm{PPh}_{3}\right)_{4}$ 可回收利用, 降低成 本(Scheme 11).

$$
\mathrm{R}=+\mathrm{ArB}(\mathrm{OH})_{2}+\mathrm{ICF}_{2} \mathrm{COOEt} \frac{\mathrm{Cs}_{2} \mathrm{CO}_{3}(1.0 \text { equiv. })}{\begin{array}{c}
\text { 1,4-dioxane, } 80{ }^{\circ} \mathrm{C} \\
8 \mathrm{~h} \text {, argon }
\end{array}}
$$

图式 11 钯催化炔烃的芳基二氟烷基化反应

Scheme 11 Pd-catalyzed aryldifluoroalkylation of alkynes

不久之后, 梁永民等 ${ }^{[22]}$ 又开发了零价铜(铜粉)催化 的炔烃与碘二氟乙酸乙酯、三甲基硅氰(TMSCN)的三组 分反应，快速合成了二氟烷基化丙烯腈产物. 这对于含 氟药物的合成, 是一项重要的发现. 该反应具有高度区 域选择性和立体选择性，但产物收率最高只有 $76 \%$
(Scheme 12).

$$
\mathrm{R}=+\mathrm{TMSCN}+\mathrm{ICF}_{2} \mathrm{COOEt} \frac{\text { Cu powder (2.0 equiv.) }}{\stackrel{\substack{\mathrm{DMSO}, 90^{\circ} \mathrm{C} \\ 12 \mathrm{~h} \text {, argon } \mathrm{EtOOCF}_{2} \mathrm{C}}}{\longrightarrow}}
$$

图式 12 铜催化炔烃的氰基二氟烷基化反应

Scheme 12 Cu-catalyzed cyano-difluoroalkylation of alkynes

钯催化剂由于具有活性高、选择性强、应用领域广、 能够反复再生和活化使用以及废催化剂中的金属钯可 以回收再利用等优越性，其发展前景广阔. 2017 年，唐 果等 ${ }^{[23]}$ 报道了以 4,5-双(二苯基膦)-9,9-二甲基氧杂葱 (Xantphos)为配体, 氯化钯为催化剂的炔烃的二氟烷基 膦氧化反应, 方便、高效地以中高产率获得各种 $(E)-\gamma, \gamma$ 二氟烷基膦氧化物. 该反应在温和的条件下进行，具有 高度的区域选择性和立体选择性，并表现出较好的官能 团耐受性，脂肪族炔烃也能以良好的收率得到目标产 物，但非末端炔烃如 1,2-二苯乙炔不适用于该反应 (Scheme 13).

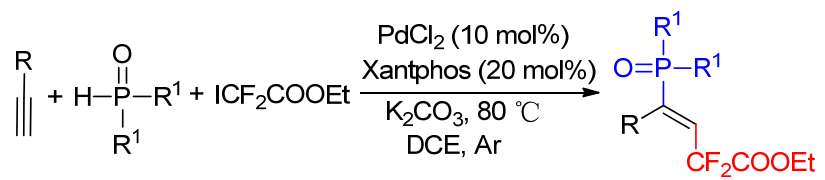

图式 13 钯催化炔烃的膦氧二氟烷基化反应

Scheme 13 Pd-catalyzed phosphinodifluoroalkylation of alkynes

2018 年，吴范宏等 ${ }^{[24]}$ 报道了钯催化 2-碘-2,2-二氟 苯乙酮、苯乙炔和芳基嗍酸的三组分反应. 该方法具有 高度的立体选择性和区域选择性，产物收率高. 生物活 性实验表明，苯并二氟-1,1-二芳基乙烯结构对人体肿瘤 细胞有一定的抗增殖活性，通过进一步的构效关系研究 可用于开发潜在的新型抗肿瘤药物(Scheme 14).

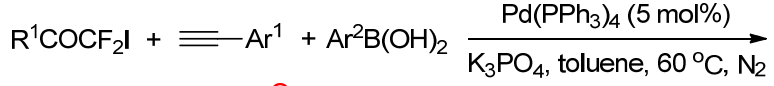

$$
\begin{aligned}
& \mathrm{Ar}^{2} \mathrm{Ar}^{1} \mathrm{~F}_{\mathrm{F}}
\end{aligned}
$$

图式 14 钯催化炔烃的芳基二氟烷基化反应

Scheme 14 Pd-catalyzed aryldifluoroalkylation of alkynes

炔烃嗍化反应是获得多取代烯烃硼化物最直接的

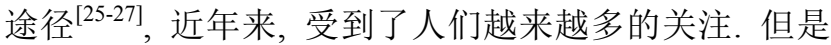
已报道的方法区域选择性不好，且非末端炔烃的反应活 性普遍不好. 2018 年, 朱钢国等 ${ }^{[28]}$ 报道了一种温和而新 颖的钯催化炔烃与氟烷基卤化物和嗍酯的嗍化氟烷基 化反应，能得到广泛的单氟、二氟、全氟烷基化烯烃硼 化物. 该反应条件可以兼容多种不同的氟烷基化试剂, 末端炔烃和非末端炔烃都有很好的收率(Scheme 15). 


$$
\begin{aligned}
& \mathrm{R}^{1} \mathrm{H}^{\mathrm{R}^{2}}+\mathrm{ICF}_{2} \mathrm{CO}_{2} \mathrm{Et}+\mathrm{B}_{2} \mathrm{pin}_{2} \frac{\mathrm{Pd}\left(\mathrm{PPh}_{3}\right)_{4}(5 \mathrm{~mol} \%)}{\mathrm{DCE}, \mathrm{N}_{2}, 80^{\circ} \mathrm{C}, 10 \mathrm{~h}} \mathrm{EtO}_{2} \mathrm{CF}_{2} \mathrm{C} \\
& \mathrm{Ph}=+\mathrm{R}_{\mathrm{f}} \mathrm{Br}+\mathrm{B}_{2} \mathrm{pin}_{2} \frac{\left.\mathrm{CsCO}_{3}\right)_{4}(15 \mathrm{~mol} \%)}{\mathrm{DCE}, \mathrm{N}_{2}, 80^{\circ} \mathrm{C}, 10 \mathrm{~h}}
\end{aligned}
$$

图式 15 钯催化炔烃的嗍化氟烷基化反应

Scheme 15 Pd-catalyzed fluoroalkylboration of alkynes

2019 年, 张新刚课题组 ${ }^{[29]}$ 报道了钯催化的炔烃与 氟烷基碘化物和 $\mathrm{B}_{2} \mathrm{pin}_{2}$ 的三组分反式嗍化氟烷基化反 应. 该反应具有良好的官能团容忍性和广泛的底物范 围，可耐受一系列氟烷基碘化物，包括二氟烷基碘化物 和全氟烷基碘化物, 且末端炔烃和非末端炔烃都能高效 地转化为目标产物. 此外得到的嗍化氟烷基化产物可转 化为有用的四取代烯烃，也可与烷基卤化物发生偶联反 应，已被成功应用于雌酚酮衍生物的结构修饰，证明了 该反应的应用潜力. 初步机理研究表明, 在反应过程中 形成了关键的反式碘氟烷基化烯烃中间体，该中间体在 钯的催化下进行嗍化反应生成了反式氟烷基化的烯基 喼酯(Scheme 16).

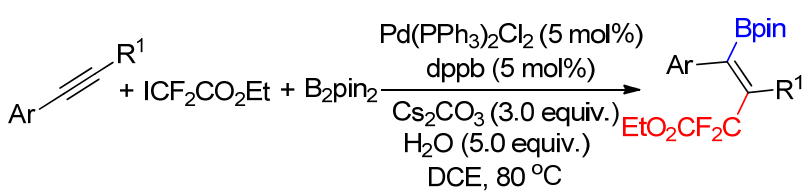

图式 16 钯催化炔烃的嗍化二氟烷基化反应

Scheme 16 Pd-catalyzed difluoroalkylboration of alkynes

\section{2 三组分参与的三氟甲基化反应}

由于三氟甲基 $\left(\mathrm{CF}_{3}\right)$ 具有强吸电子性、亲脂性和稳定 的 $\mathrm{C}-\mathrm{F}$ 键, 将其引入到有机化合物中能够显著改变化 合物的酸性、偶极距、极性、亲脂性以及其化学和代谢 稳定性 ${ }^{[2]}$. 因此含三氟甲基的化合物已在医药、农药和 材料等领域得到了广泛应用. 如治疗精神抑郁的药物百 忧解(Prozac)、治疗关节炎的药物西乐葆(Celebrex)和治 疗 II 型糖尿病的药物捷诺维(Januvia)等都含有三氟甲基 (Scheme 17). 近几十年来, 化学家们已经发展了各种不 同类型的向有机分子引入三氟甲基的反应, 但这些方法 存在反应条件苛刻、原料难得及选择差等缺点. 近年来, 在多组分反应研究的推动下, 三氟甲基化反应取得了重 大突破.

\section{1 烯烃的三组分三氟甲基化反应}

\section{1 .1 烯烃的三组分氧三氟甲基化反应}

2012 年, Akita 等 ${ }^{[30]}$ 在可见光驱动下实现了烯烃的 氧三氟甲基化反应. 在室温条件下, 利用可见光(蓝色<smiles>CNCCC(Oc1ccc(C(F)(F)F)cc1)c1ccccc1</smiles>

图式 17 含三氟甲基的代表药物

Scheme 17 Drugs containing trifluoromethyl group

LED)照射 2 4 h 即可反应. 该反应能够以极低的催化 剂用量和较高的区域选择性高效地得到相应产物, 还可 以兼容醇、羧酸以及水等多种不同的氧化试剂. 此外, 该反应条件温和，氟化试剂易于处理，还可用于从相应 的三芳基烯烃合成抗雌激素药物 Panomifene, 相信未来 这种方法在药物和农用化学品的合成方面会得到进一 步发展(Scheme 18).

$$
\begin{aligned}
& \begin{array}{c}
\text { [fac-Ir(ppy } \left.)_{3}\right](0.5 \mathrm{~mol} \%) \\
\frac{\text { Umemoto's reagent }(1.1 \text { equiv. })}{\mathrm{CH}_{2} \mathrm{Cl}_{2} / \mathrm{ROH}(\mathrm{V}: \mathrm{V}=9: 1), \text { r.t. }} \\
425 \mathrm{~nm} \text { blue LEDs } \\
2 \sim 4 \mathrm{~h}
\end{array} \\
& \mathrm{R}^{3} \underset{\substack{\text { acetone } / \mathrm{H}_{2} \mathrm{O}(\mathrm{V}: \mathrm{V}=9: 1), \mathrm{r} . \mathrm{t.} \\
425 \mathrm{~nm} \text { blue LEDs }}}{\stackrel{\text { Umemoto's reagent }(1.1 \text { equiv. })}{\text { [fac- } \left.\mathrm{Ir}(\mathrm{ppy})_{3}\right](0.5 \mathrm{~mol} \%)}} \\
& 2 \sim 4 \mathrm{~h}
\end{aligned}
$$

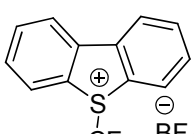

图式 18 光催化烯烃的氧三氟甲基化反应 Scheme 18 Oxygentrifluoromethylation of alkenes using photoredox catalysis

同年, Studer 等 ${ }^{[31]}$ 利用 TEMPONa、DEDMPONa 等 与 Togni 试剂开发了一种用于烯烃三氟甲基化的新方 法. 该过程包括 $\mathrm{C}-\mathrm{CF}_{3}$ 键和 $\mathrm{C}-\mathrm{O}$ 键的形成以及 $\mathrm{N}-\mathrm{O}$ 键在乙酸中被锌粉还原，最终得到各种三氟甲基 $\beta$-醇. 该反应具有良好的非对映选择性，条件简单，无需催化 剂，同时对活化烯烃和未活化烯烃都具有很好的兼容 性. 另外, 该反应过程中可能形成的副产物 $\mathrm{TEMPOCF}_{3}$ 经简单萃取即可除去, 同时 Togni 试剂可能形成的副产 物邻碘苯甲酸钠盐可经碱性萃取除去(Scheme 19). 


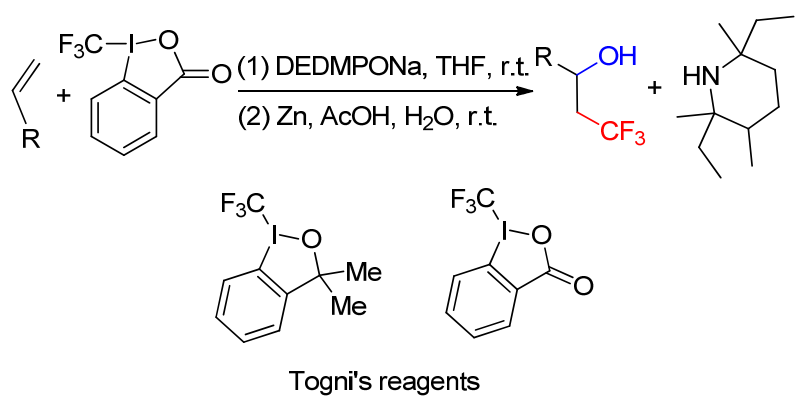

图式 19 烯烃的氧三氟甲基化反应

Scheme 19 Oxygentrifluoromethylation of alkenes

Loh 等 ${ }^{[32}$ 报道了通过直接取代烯烃 $\mathrm{C}-\mathrm{H}$ 键来实现 烯烃三氟甲基化, 值得注意的是, 在反应条件的优化过 程中发现可以通过催化剂与溶剂的控制, 得到烯酰胺的 氧三氟甲基化产物. 与已报道的方法相比, 该反应具有 良好的立体选择性, 产物收率很高, 无副产物生成, 铜 催化剂可回收利用. 此外, 底物范围广, 芳香族酰胺以 及简单的脂肪族酰胺都能顺利地以较高收率生成产物, 但是该方法只能局限于末端烯酰胺(Scheme 20).

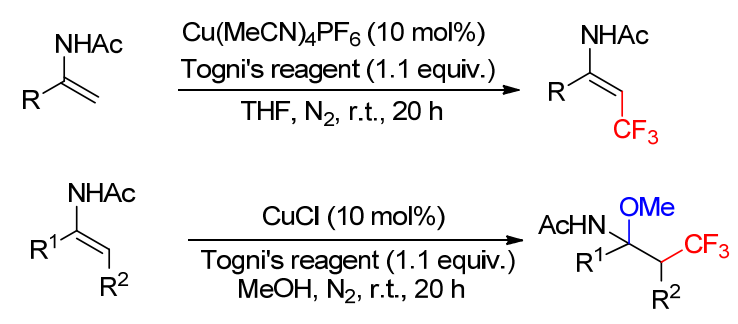

图式 20 铜催化烯酰胺的双官能团化反应

Scheme 20 Cu-catalyzed difunctionalization of alkene-amide

2014 年, Masson 等 ${ }^{[33]}$ 报道了在以 Togni 试剂为 $\mathrm{CF}_{3}$ 源, $\left[\mathrm{Ru}(\mathrm{bpy})_{3}\left(\mathrm{PF}_{6}\right)_{2}\right]$ 为光催化剂的条件下, 可通过各种 $\mathrm{O} 、 \mathrm{~N} 、 \mathrm{C}$ 亲核试剂对烯酰胺进行氧三氟甲基化反应、 叠氮三氟甲基化反应以及氧基三氟甲基化反应. 该反应 底物范围广, 链状烯酰胺以及环状烯酰胺都能得到目标 产物, 弥补了 Loh 等只能用末端烯酰胺作底物这一不 足. $\mathrm{CF}_{3}$ 的存在增强了胺的疏水性、代谢稳定性和生物利 用度, 使它们成为含氟氨基酸和多肽的重要中间体 ${ }^{[34]}$. 值得注意的是, 在某些底物中, 会有 $\beta$-碘化产物生成, 推测此副产物是由反应中产生的碘与烯酰胺发生碘化 反应而产生的, 可通过添加催化量的三苯基膦 $\left(\mathrm{Ph}_{3} \mathrm{P}\right)$ 作 为碘阱，抑制副反应的发生(Scheme 21).

2015 年, 谭斌和刘心元课题组 ${ }^{[35]}$ 为烯烃的高选择 性 1,6-双官能团化反应开发了一种新颖的、简便的非金 属自由基串联方法, 通过 $\mathrm{C}-\mathrm{CF}_{3}$ 的形成、1,5- $\mathrm{H}$ 迁移及 远程 $\mathrm{C}\left(\mathrm{sp}^{3}\right)-\mathrm{H}$ 键官能团化这一串联过程得到有价值的 含三氟甲基化合物. 另外, 也为未活化烯烃的分子间区 域选择性氧三氟甲基化提供了新策略. 其中, Togni
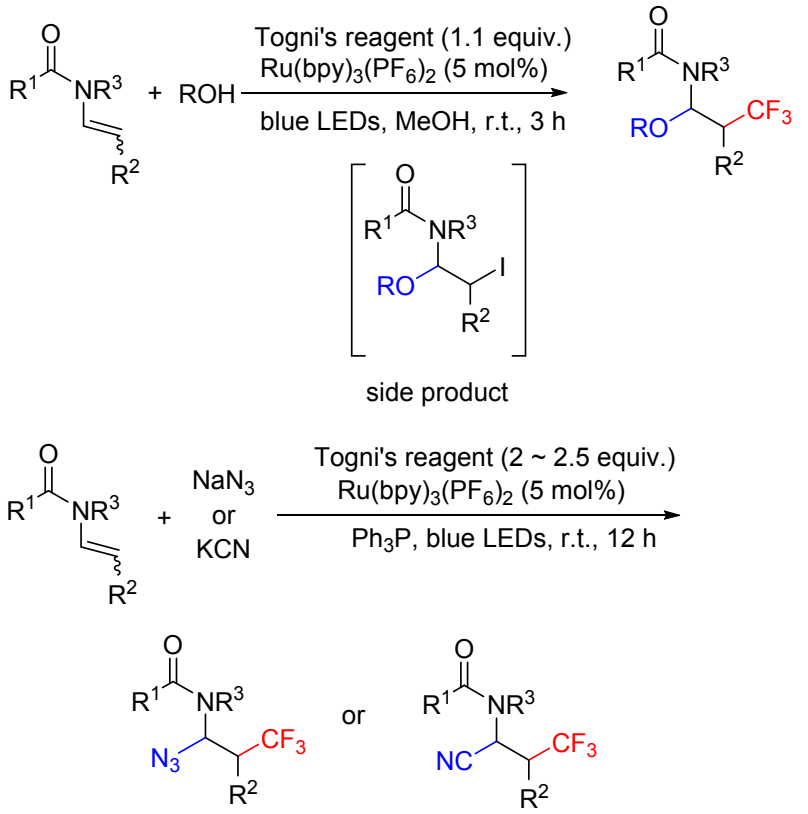

图式 21 钉催化烯酰胺的双官能团化反应

Scheme 21 Ru-catalyzed difunctionalization of alkene-amide

试剂同时作为 $\mathrm{CF}_{3}$ 源和氧化剂. 值得注意的是, 这一新 的自由基反应不仅在非金属条件下进行，而且操作简 单, 成本低廉(Scheme 22).

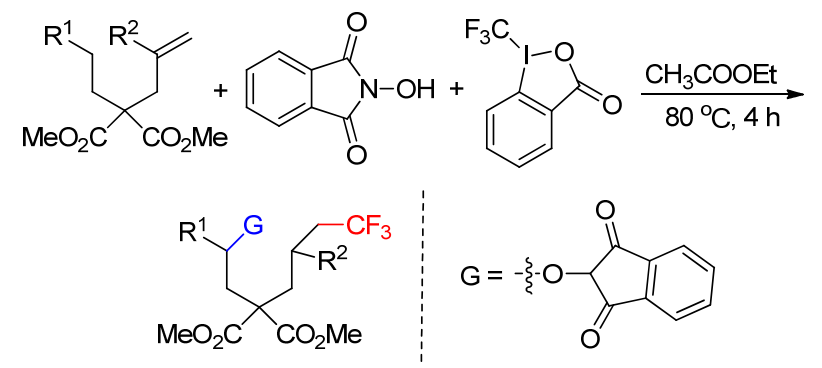

图式 22 无金属条件下烯烃的三氟甲基化反应

Scheme 22 Metal-free trifluoromethylation of alkenes

自 20 世纪 90 年代起, Langlois 和他的同事 ${ }^{[36]}$ 开始 探索三氟代甲烷亚磺酸钠 $\left(\mathrm{NaSO}_{2} \mathrm{CF}_{3}\right)$ 与富电子芳香化 合物的取代反应后, Shibata ${ }^{[37]} 、$ Baran $^{[38]}$ 和 Sanford ${ }^{[39]}$ 等 $^{\text {分 }}$ 分别研究了利用三氟代甲烷亚磺酸钠对芳烃、杂环和芳 基硼酸的三氟甲基化反应，发展了反应条件温和的三氟 甲基化反应.

2013 年, 卿凤翎等 ${ }^{[40]}$ 报道了铜催化的烯烃与三氟 代甲烷亚磺酸钠 $\left(\mathrm{NaSO}_{2} \mathrm{CF}_{3}\right)$ 和 $N$-羟基- $N$-苯基乙酰胺的 氧三氟甲基化反应. 该反应以羟肜酸为自由基引发剂, 采用稳定廉价的 $\mathrm{NaSO}_{2} \mathrm{CF}_{3}$ 作为 $\mathrm{CF}_{3}$ 源, 成本低廉, 反应 条件温和, 具有良好的官能团容忍性. 值得注意的是, $\mathrm{CuSO}_{4} \cdot 5 \mathrm{H}_{2} \mathrm{O}$ 是一种有效的三氟甲基化催化剂, 在此反 应中有利于提高产物的区域选择性(Scheme 23). 


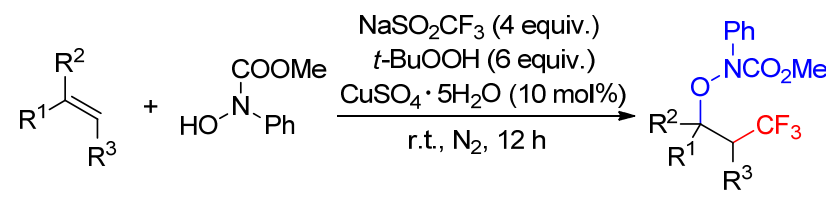

图式 23 铜催化烯酰胺的氧三氟甲基化反应

Scheme 23 Cu-catalyzed oxygentrifluoromethylatio of alkeneamide

\subsection{2 烯烃的三组分氮/三氟甲基化反应}

含氮有机化合物在药物和功能材料中占有重要地 位. 由于含氟基团能够改变化合物的物理性质和生物活 性, 含氟烷基胺类化合物更是制药和农业化学品的重要 中间体.

2014 年, 刘国生等 ${ }^{[41]}$ 报道了一种新型的铜催化烯 烃分子间叠氮三氟甲基化反应，在温和的反应条件下， 一步生成含 $\mathrm{CF}_{3}$ 的叠氮化合物, 该叠氮化合物可以很容 易地转化为一系列极有价值的含 $\mathrm{CF}_{3}$ 的胺类衍生物. 该 反应具有良好的官能团耐受性和广泛的底物范围, 无论 是活化烯烃还是未活化烯烃都适用于这种转化, 为含 $\mathrm{CF}_{3}$ 氨基酸的合成提供了一条有效的途径(Scheme 24).

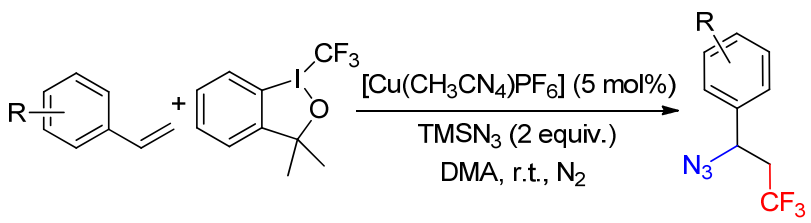

图式 24 铜催化烯烃的分子间三氟甲基化反应

Scheme 24 Cu-catalyzed intermolecular trifluoromethylation of alkenes

Masson 等 ${ }^{[42]}$ 在光催化条件下, 以便宜易得的 $\mathrm{TMSN}_{3}$ 作为叠氮试剂, Umemoto's 试剂为三氟甲基化试 剂, 成功开发了一种新型的烯烃叠氮化三氟甲基化反 应. 该反应具有很好的区域选择性, 反应条件温和, 末 端烯烃和非末端烯烃都能高产率地转化为相应的三氟 甲基化合物. 更为突出的是, 芳环上有供电子基团或吸 电子基团的苯乙烯衍生物都可以反应. 不足之处是, 用 一级或二级胺代替 $\mathrm{TMSN}_{3}$ 时没有三氟甲基化产物生成, 苯胺也是同样的结果. 在相同条件下, 只有当苯胺上带 有吸电子基团时, 反应才顺利进行, 氨基三氟甲基化产 物的收率可达到 $43 \% \sim 66 \%$ (Scheme 25).

2018 年, 张国柱等 ${ }^{[43]}$ 报道了一种新的铜催化烯烃 与甲烷亚磺酸钠 $\left(\mathrm{MeSO}_{2} \mathrm{Na}\right)$ 和 $\mathrm{TMSN}_{3}$ 的自由基磺化叠 氮化反应, 在相同的条件下, 以三氟代甲烷亚磺酸钠 $\left(\mathrm{CF}_{3} \mathrm{SO}_{2} \mathrm{Na}\right)$ 或二氟代甲烷亚磺酸钠 $\left(\mathrm{CHF}_{2} \mathrm{SO}_{2} \mathrm{Na}\right)$ 代替 $\mathrm{MeSO}_{2} \mathrm{Na}$, 可以很容易地得到叠氮氟烷基化产物, 这是 使用 $\mathrm{NaSO}_{2} \mathrm{CHF}_{2}$ 的二氟甲基化反应. 该反应原料易得, 反应条件温和, 底物范围广泛, 在有机合成和药物化

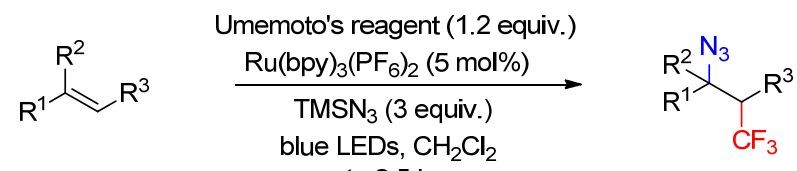

r.t., $2.5 \mathrm{~h}$

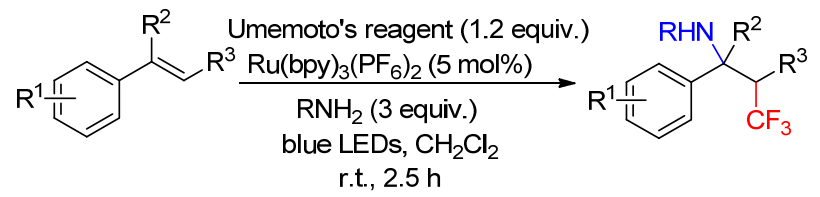

图式 25 钉催化烯烃的叠氮/胺三氟甲基化反应

Scheme 25 Ru-catalyzed azidotrifluoromethylation and aminotrifluoromethylation of alkenes

学中的应用潜力巨大(Scheme 26).

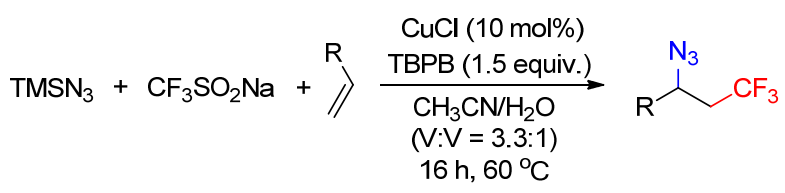

图式 26 铜催化烯烃的叠氮三氟甲基化反应

Scheme 26 Cu-catalyzed azidotrifluoromethylation of alkenes

邻位三氟甲基伯胺是一种非常有价值的构建模块, 经常被用在药物分子和生物探针中 ${ }^{[44]}$. 烯烃的叠氮三 氟甲基化反应是目前合成这些模块最直接的方法之一， 但是没有完全解决各种医药相关的邻位三氟甲基胺的 合成 ${ }^{[44]} .2018$ 年, 顼吴等 ${ }^{[45]}$ 报道了一种独特的铁催化烯 烃叠氮三氟甲基化反应高效合成邻位三氟甲基伯胺的 方法. 该方法适用于各种烯烃和 $\mathrm{N}$-杂环化合物, 底物范 围广泛，在温和的反应条件下生成许多其他方法难以制 备的邻位三氟甲基伯胺类化合物. 初步的机理研究表 明，催化促进的叠氮基转移是通过碳自由基进行的，而 不是通过碳正离子. 原位生成的新型叠氮化铁配合物可 以促进氧化剂的活化和选择性叠氮基团的转移(Scheme 27).

\section{1 .3 烯烃的三组分硫/三氟甲基化反应}

有机含硫化合物是生物活性化合物中普遍存在的 具有抗菌或抗增殖活性的部分, 也是构建各种杂环化合 物的通用模块, 因此, 寻找有效的方法将硫代基团引入 到有机分子中，受到越来越多的关注.

2015 年, 刘国生课题组 ${ }^{[46]}$ 以三甲基硅烷异氰酸酯 (TMSNCS)作为硫氰基源，Togni 试剂作为三氟甲基源， 在 $\mathrm{Cu}(\mathrm{I})$ 的催化作用下, 同时将硫氰基和三氟甲基引入 烯烃分子中. 这一反应化学选择性高, 条件温和, 底物 普适性及官能团兼容性都比较好. 同时, 得到的含硫氰 基的有机化合物是生物活性化合物中普遍存在的具有 抗菌素 ${ }^{[47]}$ 或抗增殖活性 ${ }^{[48]}$ 的分子，展示了这一新反应 方法的潜力(Scheme 28). 
<smiles>[R]C=C([R])[R]</smiles>

(a) $\mathrm{Fe}(\mathrm{OAc})_{2}-\mathrm{L} 2(10 \mathrm{~mol} \%)$ $\mathrm{TMSN}_{3}$ (1.5 equiv.) $\mathrm{CH}_{2} \mathrm{Cl}_{2} / \mathrm{MeCN}, 22^{\circ} \mathrm{C}$

(b) $\mathrm{Pd} / \mathrm{C}(10 \mathrm{wt} \%), \mathrm{H}_{2}$; then $\mathrm{TsOH} \cdot \mathrm{H}_{2} \mathrm{O}$ (1.1 equiv.) or $\mathrm{Boc}_{2} \mathrm{O}$ (1.2 equiv.)

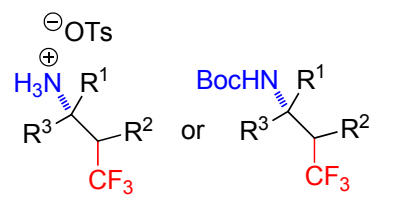<smiles>CC1(C)COC(c2ccccn2)=N1</smiles>

$N$-heterocycles

or

terpenes<smiles>C[As](C)(C)[C+]1OC(=O)c2ccccc21</smiles>

(a) Fe" catalyst ligand

(b) reduction protection vicinal aminotrifluoromethylated $\mathrm{N}$-heterocycles or terpenes

图式 27 铁催化烯烃和 $N$-杂环的叠氮三氟甲基化反应 Scheme 27 Iron-catalyzed azidotrifluoromethylation of olefins and $N$-heterocycles

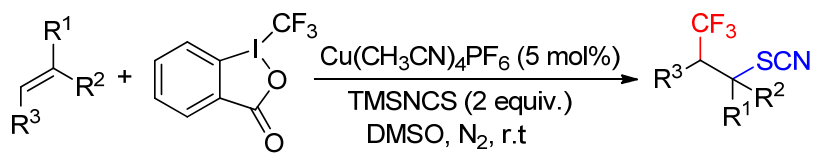

图式 28 铜催化烯烃的硫氰基三氟甲基化反应

Scheme $28 \mathrm{Cu}$-catalyzed trifluoromethylthiocyanation of alkenes

2017 年, 宋秋玲等 ${ }^{[49]}$ 采用 $\mathrm{NaSO}_{2} \mathrm{CF}_{3}$ 为 $\mathrm{CF}_{3}$ 源, 以 硫代苯基砜为硫源, 实现了在可见光诱导下末端烯烃的 硫三氟甲基化反应. 该反应具有良好的官能团相容性, 底物范围广, 脂肪族末端烯烃也可反应, 但以 $S$-烷基苯 基砜为硫源时, 无产物生成, 这可能是由于 $S$-烷基苯基 砜的亲电性较弱的缘故. 该反应已被应用于雌激素酮衍 生物的三氟甲基化中，产物收率达 41\%，且硫三氟甲基 化产物也可以用间氯过氧化苯甲酸 $(m-\mathrm{CPBA})$ 氧化为其 砜类衍生物(Scheme 29).

\section{1 .4 烯烃的其他三组分三氟甲基化反应}

有机腈类化合物因其具有多种多样的化学性质和 生物活性, 在许多医药、农业化学品和光电子材料中都 有应用 ${ }^{[50]}$. 如果能同时将 $\mathrm{CF}_{3}$ 和氰基引入有机化合物 中, 可能改变母体结构的生物活性, 成为一类有价值的 药物分子结构修饰策略.

梁永民等 ${ }^{[51]}$ 和 Szabó等 ${ }^{[52]}$ 分别报道了铜催化的烯烃 氰基三氟甲基化反应，使用的是活性较强的酯型 Togni 试剂. 相比较而言, 梁永民的方法底物范围广, 适用于各 种苯乙烯衍生物和未活化烯烃, 收率高, 但反应条件更 加苛刻. Szabó的方法底物范围窄, 只适用于苯乙烯衍生 物，但反应条件温和(Scheme 30).

在此研究基础之上, 刘国生等 ${ }^{[53]}$ 又顺利研发了一 种铜催化烯烃分子间氰基三氟甲基化反应. 该反应使用

$$
\begin{aligned}
& \mathrm{R}^{1} \curvearrowright+\mathrm{PhSO}_{2} \mathrm{SR}^{2}+\mathrm{CF}_{3} \mathrm{SO}_{2} \mathrm{Na} \frac{\operatorname{Ir}\left[\mathrm{dF}\left(\mathrm{CF}_{3}\right) \mathrm{ppy}_{2}\left(\mathrm{PF}_{6}\right)(2.5 \mathrm{~mol} \%)\right.}{5 \mathrm{~W} \text { blue } \mathrm{LED} \text {, r.t., } 18 \mathrm{~h}} \\
& \overbrace{}^{\mathrm{SR}^{2}} \mathrm{CF}_{3}
\end{aligned}
$$

图式 29 光催化末端烯烃的硫三氟甲基化反应

Scheme 29 Sultrifluoromethylation of terminal alkenes using photoredox catalysis
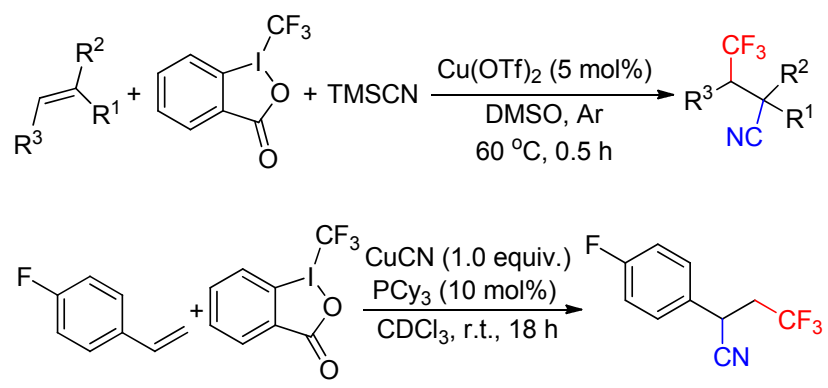

图式 30 铜催化烯烃的氧基三氟甲基化反应

Scheme $30 \mathrm{Cu}$-catalyzed cyanotrifluoromethylation of alkenes

反应活性较低的 Togni 试剂作为 $\mathrm{CF}_{3}$ 源, TMSCN 作为氰 基源, 具有很广泛的底物范围, 链状烯烃、环状烯烃以 及一些共轭烯烃都可作为底物(Scheme 31).

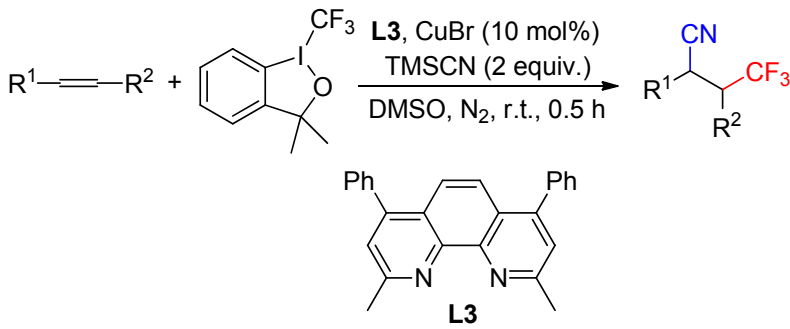

图式 31 铜催化烯烃的氰基三氟甲基化反应

Scheme $31 \mathrm{Cu}$-catalyzed cyanotrifluoromethylation of alkenes

2016 年, 刘国生课题组 ${ }^{[54]}$ 再次报道了烯烃的氰基 三氟甲基化反应，在 $\mathrm{Cu}(\mathrm{I})$ /手性双噁唑啉催化下，得到 了对映体富集的含 $\mathrm{CF}_{3}$ 的有机氰化物. 该反应具有高 效、显著的对映选择性和优良的官能团相容性，但相比 之下，乙烯基杂环芳烃的对映体选择性略低. 同时该反 应也存在一些局限性: (1) 1,1-二取代烯烃反应性差; (2) 脂肪族末端烯烃具有良好的反应活性，但对映体的选择 性较差; (3)用无机氰化物，如 $\mathrm{NaCN}$ 和 $\mathrm{KCN}$ 代替 TMSCN，无法得到目标产物(Scheme 32).

2019 年, 王细胜等 ${ }^{[55]}$ 再次报道了 $\mathrm{Cu}(\mathrm{acac})_{2}$ 催化的 乙烯基环丙烷对映选择性 1,5-氰基三氟甲基化反应. 这 种不对称反应具有对映体选择性强、底物范围广及反应 条件温和等特点, 为烯烃类化合物的远端对映选择性双 官能化提供了一种新的方法，同时也为含 $\mathrm{CF}_{3}$ 和手性氰 基的分子内烯烃开辟了一条新的合成途径. 此外，以 3- 

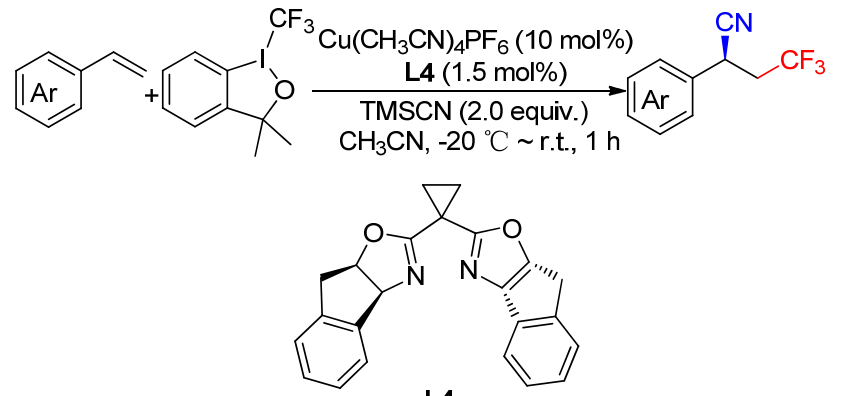

L4

图式 32 铜催化烯烃的对映选择性氰基三氟甲基化反应

Scheme 32 Cu-catalyzed enantioselective cyanotrifluoromethylation of alkenes

氯过氧苯甲酸 ( $m$-CPBA) 为氧化剂, 可进一步将产物转 化为各种含 $\mathrm{CF}_{3}$ 的环氧化合物. 值得注意的是, $E / Z$ 选择 性与碳碳双键上取代基的空间位阻密切相关; 未活化乙 烯基环丙烷作为反应底物, 只能得到微量目标产物 (Scheme 33).
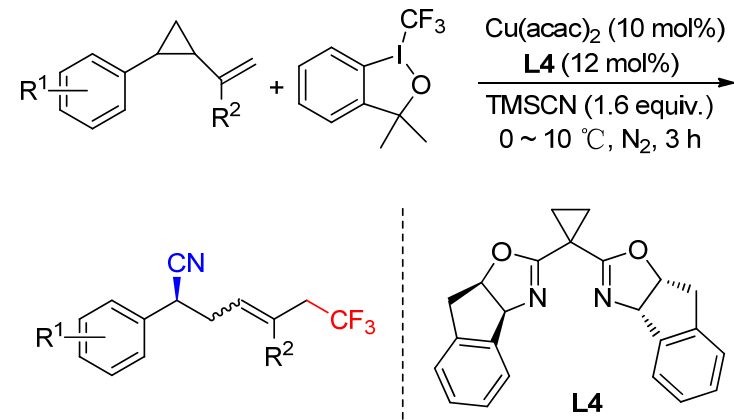

图式 33 铜催化乙烯基环丙烷的对映选择性 1,5-㲵基三氟甲 基化反应

Scheme 33 Cu-catalyzed enantioselective 1,5-cyanotrifluoromethylation of vinylcyclopropanes

2016 年, Masson 等 ${ }^{[56]}$ 以 Umemoto's 试剂为 $\mathrm{CF}_{3}$ 源, 高效地合成了多种含 $\mathrm{CF}_{3}$ 的邻苯二甲酸类化合物 $(1,3-二$ 氢异苯并呋喃类化合物)和 1,3-二取代异吲哚类化合物. 该反应产率高, 非对映选择性好, 底物范围广, 为异吲 哚-1-羧酸的合成提供了快速通道, 它是制备生物活性 化合物的重要骨架 ${ }^{[57]}$ (Scheme 34).

由于 $\beta$-三氟甲基腈类化合物在调节药物分子的物 理化学性质、药代动力学和药效学方面的独特特性, 其 在药物和农药中占有相当大的比例. 2018 年, 王永辉 等 ${ }^{[58}$ 报道了烯烃在含水溶剂中进行的氧三氟甲基化反 应, 高效地合成了在化学和医药行业有广泛应用的 $\beta$-三 氟甲基腈. 该反应以易得的三氟代甲烷亚磺酸钠为三氟 甲基源, 成本低廉, 同时具有良好的官能团相容性和较 广泛的底物范围. 而且, 在相同的反应条件下, 可以得 到中等产率的 $\beta$-二氟甲基腈(Scheme 35).

1,3-烯炔作为一类特殊的烯烃, 其 1,2-加成反应已

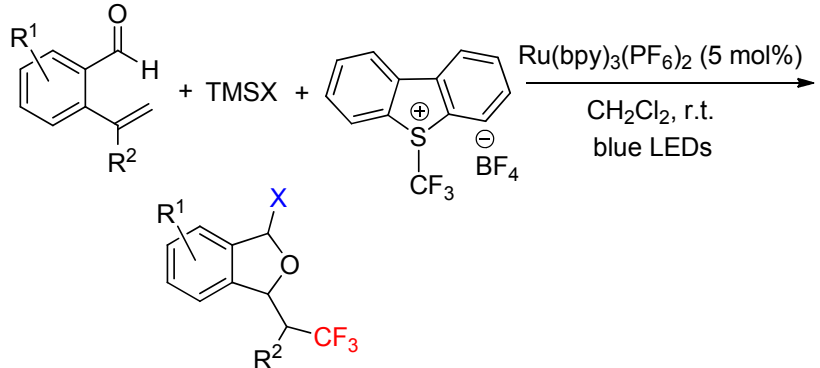

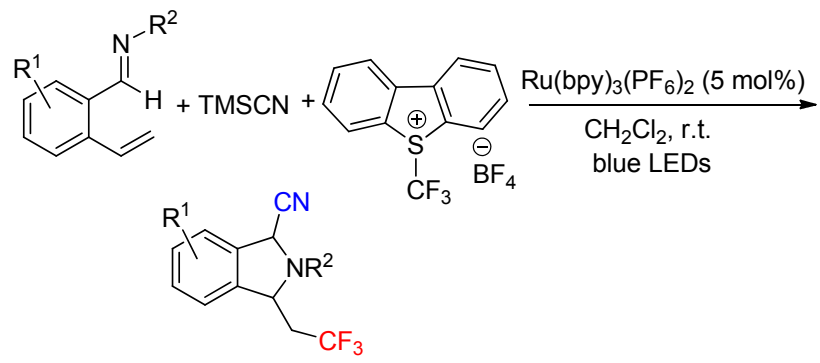

图式 34 钉催化烯烃的三氟甲基化反应

Scheme 34 Ru-catalyzed Trifluoromethylation of Alkenes

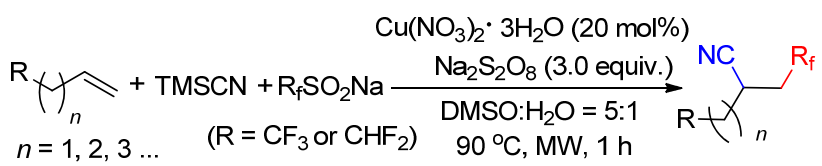

图式 35 铜催化烯烃的氰基氟烷基化反应

Scheme 35 Cu-catalyzed cyanofluoroalkylation of alkenes

得到广泛研究 ${ }^{[59]}$, 但相关的 1,4-加成反应鲜有报道 ${ }^{[60]}$. 2018 年, 刘国生等 ${ }^{[61]}$ 报道了铜催化 1,3-烯炔的三氟甲基 氧化反应，通过配体控制，实现了可调谐的 1,2-/ 1,4-自 由基加成反应，选择性地生成相应的含 $\mathrm{CF}_{3}$ 取代的丙炔 和烯丙基产物. 值得注意的是，反应结束后，将反应粗 品用 $\mathrm{Et}_{3} \mathrm{~N}$ 处理后, 丙炔氧化物以 $86 \%$ 的产率异构化为 烯丙氰化物. 此外, 该反应具有广泛的底物范围和良好 的官能团相容性，可以获得多种含 $\mathrm{CF}_{3}$ 的三取代和四取 代烯基腈. 更重要的是, 不同于传统的自由基过程, 该 反应中 1,3-烯炔的 1,2-和 1,4-双官能团化都可以实现, 这种可调的自由基的区域选择性将对有机金属化学选 择性控制的催化体系的发展具有重要意义(Scheme 36). 2014 年, 刘国生等 ${ }^{[62]}$ 报道了一种新型的铜催化烯烃的 芳基三氟甲基化反应，以 Togni 试剂为 $\mathrm{CF}_{3}$ 源，芳基硼 酸为芳基化试剂, 能有效地合成各种含 $\mathrm{CF}_{3}$ 的 1,1-二芳 基乙烷衍生物, 反应高效, 底物范围广泛, 芳基以及烷 基的末端烯烃都可以在这个体系中取得很好的效 2017 年, 刘国生等 ${ }^{[63]}$ 在这一难题上取得突破，为制备具有良 好对映体选择性的 1,1-二芳基乙烷衍生物提供果. 不足 之处是由于茮基自由基的高反应活性，使得该反应的对 映选择性不理想(Scheme 37). 


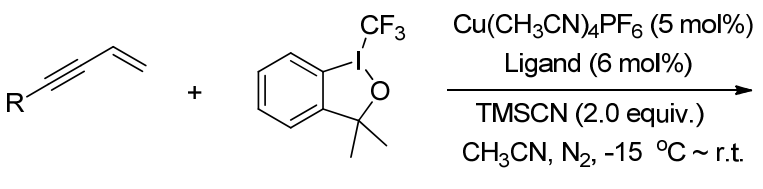

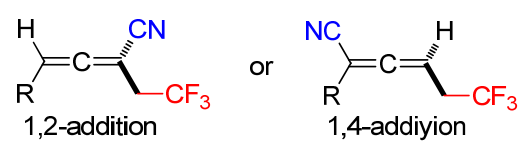

图式 36 铜催化 1,3-烯炔的三氟甲基氰化反应

Scheme 36 Cu-catalyzed cyanotrifluoromethylation of 1,3enynes

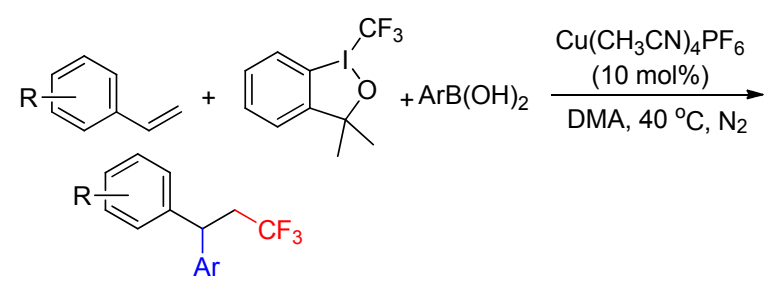

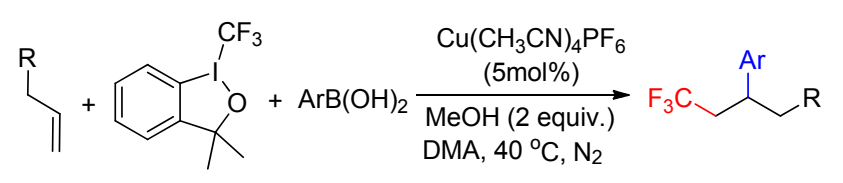

图式 37 铜催化烯烃的芳基三氟甲基化反应

Scheme $37 \mathrm{Cu}$-catalyzed aryltrifluoromethylation of alkenes

了一种灵活、高效且简便的方法(Scheme 38). 该反应具 有优良的对映体选择性, 但反应条件苛刻, 成本高, 底 物范围窄，只能应用于芳基乙烯.

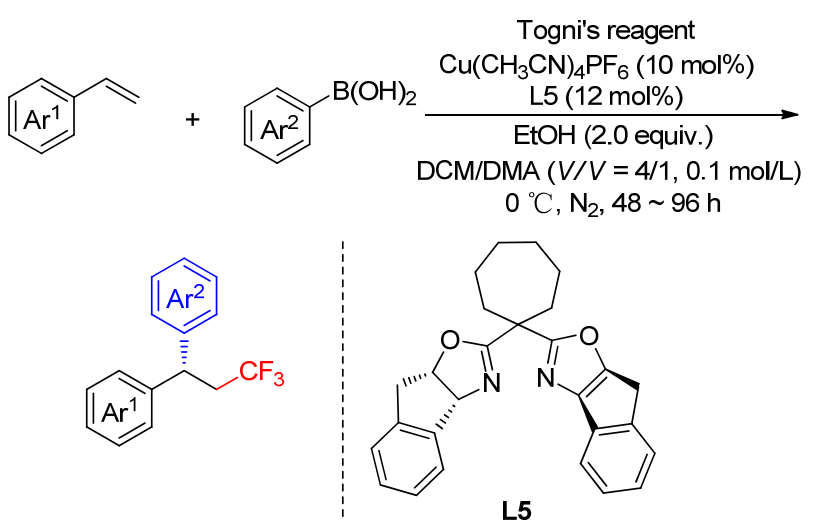

图式 38 铜催化芳基乙烯的芳基三氟甲基化反应

Scheme 38 Cu-catalyzed aryltrifluoromethylation of aryl-ethylene

2016 年, 余达刚课题组 ${ }^{[64]}$ 利用无毒易得的温室气 体 $\mathrm{CO}_{2}$ 与烯丙胺在铜催化作用下和 Togni 试剂发生氧三 氟甲基化反应, 高效高选择性地合成了具有生理活性的 含三氟甲基的 2-噁唑烷酮类化合物. 该反应在氧化还原 中性的温和条件下进行，且具有高化学选择性、区域选 择性及非对映选择性. 此外, 该反应还具有良好的官能 团兼容性及底物拓展性, 易实现产品的多样化(Scheme 39).

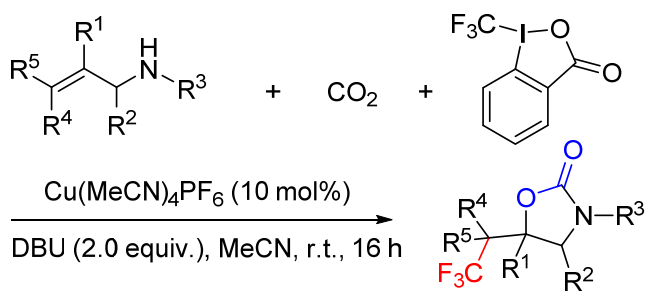

图式 39 铜催化烯烃与二氧化碳的双官能团化反应 Scheme $39 \mathrm{Cu}$-catalyzed difunctionalization of alkenes with $\mathrm{CO}_{2}$

2017 年，李超忠课题组 ${ }^{[65]}$ 报道了 2,4,6-三甲基吡啶 催化的未活化烯烃的炔基三氟甲基化反应，以 Togni 试 剂为 $\mathrm{CF}_{3}$ 源，在非金属的条件下与炔基砜类反应生成 $\beta$ 三氟甲基化炔类化合物，反应底物范围广，官能团兼容 性好，反应可能经历了非链式自由基反应历程(Scheme $40)$.

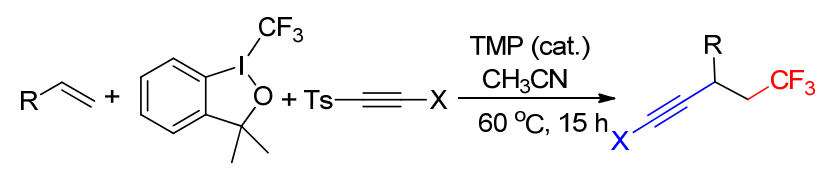

图式 40 无金属条件下未活化烯烃的炔基三氟甲基化反应 Scheme 40 Metal-free alkynyltrifluoromethylation of unactived Alkenes

2018 年，刘国生等 ${ }^{[66]}$ 报道了一种新颖的铜催化活 化烯烃的炔基三氟甲基化反应，在非常温和的条件下通 过自由基传递过程以高产率和极好的对映选择性获得 了结构多样的含 $\mathrm{CF}_{3}$ 基团的炔基化合物. 该反应底物范 围广，官能团容忍性好. 此外炔基三氟甲基化产物可以 很容易地转化为具有综合用途的手性末端炔烃、丙二 烯、 $Z$-烯烃及 $\mathrm{CF}_{3}$ 修饰的非甾体抗炎药，如布洛芬等 (Scheme 41).

含氟酮是药物分子和功能材料中最受欢迎的结构 之一. 例如, $\beta$-三氟甲基化酮存在于多种抗惊厥药和抗 糖尿病药物中 ${ }^{[67]}$. 因此, 开发高效实用的含氟酮的合成 方法具有重要意义. 近期, 李青竹等 ${ }^{[68]}$ 报道了一种在芳 香醛和亲电氟烷基试剂存在下，由 $\mathrm{N}$-杂环卡宾(NHC)催 化的烯烃通过单电子转移的多组分酰氟甲基化反应. $\mathrm{NHC}$ 有机催化可以兼容广泛的烯烃底物, 包括苯乙烯、 环内烯烃、乙烯醚、乙烯酯和未活化烯烃, 实现烯烃的 直接酰基三氟甲基化. 值得注意的是，该方法也适用于 各种二氟烷基溴化物，还可以实现全氟烷基化. 在此基 础上，他们合成了 120 多个具有不同氟取代基的酮类化 合物, 收率高达 $99 \%$, 且反应具有完全的区域选择性, 进一步突出了其实用性(Scheme 42).

\section{2 炔烃的三组分三氟甲基化反应}

$2 H$-氮杂丙烯啶是在天然产物中发现的一种非常有 


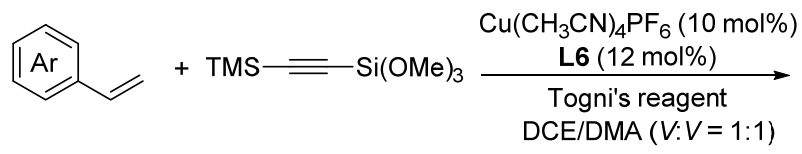

$\mathrm{N}_{2}$, r.t., $36 \sim 64 \mathrm{~h}$
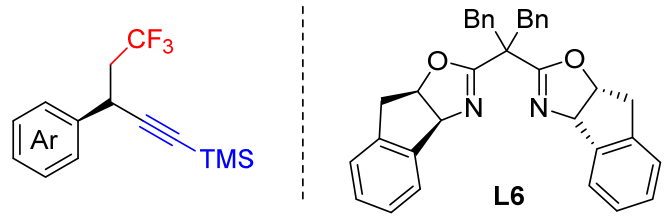

图式 41 铜催化活化烯烃的炔基三氟甲基化反应

Scheme 41 Cu-catalyzed alkynyltrifluoromethylation of actived alkenes

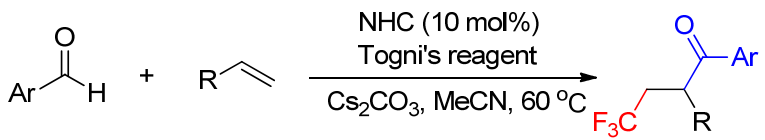

图式 $42 \mathrm{NHC}$ 催化烯烃的酰基三氟甲基化反应

Scheme 42 Acyltrifluoromethylation of alkenes using NHC catalysis

价值的化合物, 作为有机合成中用途广泛的中间体, 参 与了各种吡啶、吲哚和吡咯的合成 ${ }^{[69]} .2015$ 年, 梁永民 等 ${ }^{[70]}$ 报道了铜催化炔烃的分子间双官能团化反应，高 效地合成了多种 $\beta$-三氟甲基化丙烯腈和三氟甲基取代 的 $2 H$-氮杂丙烯啶. 而 $\beta$-三氟甲基化丙烯腈可以转化为 相关的含 $\mathrm{CF}_{3}$ 的胺和羧酸, $2 \mathrm{H}$-氮杂丙烯啶可以转化为各 种含 $\mathrm{CF}_{3}$ 的吡啶和吡嗪. 该方法可广泛用于许多生物活 性分子的合成中, 为进一步构建各种含 $\mathrm{CF}_{3}$ 的杂环提供 了一种潜在的策略(Scheme 43).
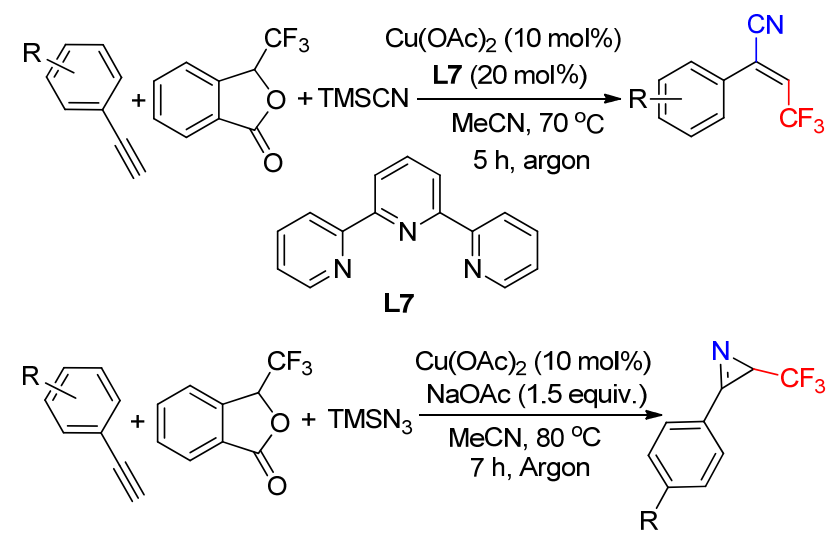

图式 43 铜催化 $\beta$-三氟甲基化丙烯腈和三氟甲基 $2 H$-氮杂丙 烯啶的合成

Scheme $43 \mathrm{Cu}$-catalyzed synthesis of $\beta$-trifluoromethylated acrylonitriles and trifluoromethyl-substituted $2 H$-azirines

铜(I)催化叠氮-炔烃 1,3-偶极环加成(CuAAC)反应 是点击化学中组装复杂分子最可靠的方法之一, 可在极 温和的条件下利用末端炔烃合成 1,4-二取代-1,2,3-三唑 类化合物, 但反应的区域选择性高度依赖于底物. 高效
合成具有高度区域选择性的氟取代的 1,2,3-三唑一直是 一个重要但具有挑战性的工作 ${ }^{[71]}$, 特别是 5-三氟甲基1,2,3-三唑，属于三氟甲基化杂环类化合物，在医药和 农药领域有着广泛应用.

2017 年, Tsui 等 ${ }^{[72]}$ 报道了 $\mathrm{Cu}(\mathrm{I})$ 催化的中断点击反 应，利用三氟甲基硅烷 $\left(\mathrm{TMSCF}_{3}\right)$ 作为亲核 $\mathrm{CF}_{3}$ 源拦截 $\mathrm{CuAAC}$ 循环, 从易得的末端炔烃和叠氮化物一步合成 了 5-三氟甲基 1,2,3-三唑. 该反应具有完全的区域选择 性，底物范围广，官能团耐受性好，已在抗癫痫药物卢 非酰胺(Rufinamide)的合成中得到了应用，证实了该方 法在药物合成中的潜力(Scheme 44).

$$
\mathrm{N}_{3}-\mathrm{R}^{2}+\mathrm{TMSCF}_{3}+\equiv \mathrm{R}^{1} \frac{\begin{array}{c}
\text { Cul }(10 \sim 20 \mathrm{~mol} \%) \\
\text { phen }(11 \sim 22 \mathrm{~mol} \%)
\end{array}}{\underset{\begin{array}{c}
\mathrm{Ag}_{2} \mathrm{CO}_{3}, \mathrm{Et}_{3} \mathrm{~N} \\
\text { DMF, r.t., } 15 \mathrm{~h} \\
\text { up to } 87 \%
\end{array}}{\longrightarrow}}
$$

图式 44 铜催化活化炔烃的三氟甲基化反应

Scheme 44 Cu-catalyzed trifluoromethylation of alkynes

空气是一种理想的氧化剂，具有安全、含量丰富、 成本低及易于处理等优点. 然而, 以空气为氧化剂的催 化好氧氧化反应由于其活性较低及选择性较差, 仍然具 有挑战性. 2019 年，李凌君等 ${ }^{[73]}$ 报道了以甘氨酰胺 (glycinamide)为配体, 空气作为氧化剂的氧化偶联反应, 以氟烷基试剂、末端炔烃和有机叠氮化物为原料，通过 一锅反应合成了多种 5-氟烷基-1,2,3-三唑. 该反应中空 气作为唯一的氧化剂, 大大降低了反应成本, 具有广泛 的底物范围和良好的官能团兼容性，为制备 5-氟烷基 1,2,3-三唑提供了一种有价值的方法, 在医药和农用化 学品方面具有很大的应用价值(Scheme 45).

$$
\mathrm{N}_{3}-\mathrm{R}^{1}+\mathrm{TMSCF}_{3}+\equiv \mathrm{R}^{2} \frac{\begin{array}{c}
\text { Glycinamide Ligand } \\
\mathrm{CuCl} \text {, air, phen }
\end{array}}{\mathrm{DME} \text {, r.t. }}
$$

图式 45 铜催化活化炔烃的氟烷基化反应

Scheme 45 Cu-catalyzed fluoroalkylation of alkynes

\section{3 其他三组分的三氟甲基化反应}

2012 年, 卿凤翎课题组 ${ }^{[74]}$ 将三氟甲基化反应拓展 到三氟甲硫基化反应，实现了铜催下芳基硼酸与亲核三 氟甲基化试剂 $\left(\mathrm{CF}_{3} \mathrm{SiMe}_{3}\right)$ 、硫粉的三组分偶联反应，发 展了一种向有机分子引入三氟甲硫基的新方法，该反应 条件温和，操作简便(Scheme 46).

\section{3 三组分参与的全氟烷基化反应}

全氟烷基化合物是非常重要的含氟化合物，往有机 分子中引入全氟烷基基团能够增强分子的结合选择性, 


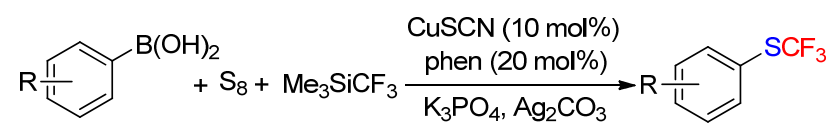

图式 46 铜催化芳基嗍酸的三氟甲硫基化反应 Scheme $46 \mathrm{Cu}$-catalyzed sultrifluoromethylation of arylboronic acid

提高亲油性, 或改善代谢稳定性, 因此被广泛地应用于 医药和农药中. 过去全氟化主要通过双组分模式, 三组 分全氟化是一种新颖的合成方式, 因其具有效率高及选 择性好等优点，受到人们越来越多的关注.

\section{1 烯烃的三组分全氟烷基化反应}

2018 年, Studer 等 ${ }^{[75]}$ 提出一种以硼酯作为硼源, 全 氟烷基卤化物作为自由基前体，对未活化烯烃进行无过 渡金属催化的嗍全氟烷基化反应. 该反应具有高度的区 域选择性，底物范围广，烯丙基芳烃衍生物、脂肪族链 状烯烃以及环状烯烃等均有良好的产物收率, 此外各种 全氟烷基碘化物 $\left[\mathrm{CF}_{3}\left(\mathrm{CF}_{2}\right)_{n} \mathrm{I}, n=0 、 2 、 5 、 7 、 9\right]$ 、碘二 氟乙酸乙酯以及四氯化碳等都可作为自由基前体. 值得 注意的是, 烷基嗍酸酯还可以进行各种后续化学反应, 如可先经过氧化生成差基化产物, 然后用碘化钾进一步 氧化以极好的产率得到氟化烯酮, 还可以利用硼酯基团 进行各种取代反应. 此外, 非金属催化使得该反应廉价 温和, 更符合绿色化学的要求(Scheme 47).

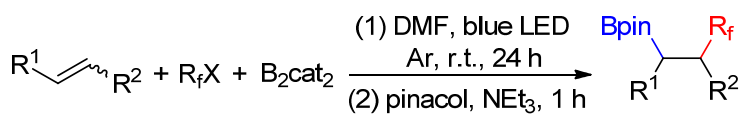

图式 47 无金属条件下未活化烯烃的硼酯全氟烷基化反应 Scheme 47 Metal-free boronperfluoroalkylation of unactived alkenes

相对于被广泛研究的碳碳双键分子间自由基加成 反应，碳氮双键分子间自由基加成反应的相关报道较 少 ${ }^{[76]} .2019$ 年, Studer 课题组 ${ }^{[77]}$ 报道了无金属催化的未 活化烯烃的 $\alpha$-全氟烷基- $\beta$-杂芳基化反应. 这种三组份 自由基串联反应以 2-(1H)-喹诺啉作为自由基受体，在 温和的条件下，以中等至优良的产率合成了一系列含全 氟烷基的 2-(1H)-喹诺啉衍生物, 其再与 $\mathrm{POCl}_{3}$ 反应, 以 $80 \%$ 的产率得到有价值的氯化喹啉, 表明了该方法在药 物化学领域有重要价值. 初步的研究机理表明, 反应通 过酸性的氨基自由基进行，氨基自由基很容易被 1,5-二 氮杂二环 [5.4.0]十一烯-5 (DBU)去质子化, 产生的相应 的自由基阴离子作为单电子转移还原试剂维持自由基 链, 因此, 整个串联过程被归类为电子催化过程 (Scheme 48).

2018 年, 储玲玲课题组 ${ }^{[78]}$ 利用还原偶联策略, 成功 发展了镍催化烯烃三组分全氟烷基碳酰化反应，并利用

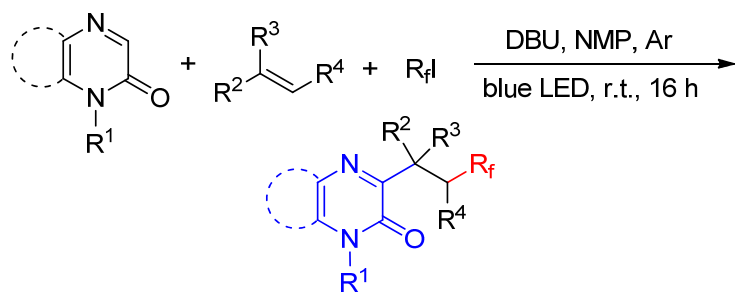

图式 48 无金属条件下未活化烯烃的 $\alpha$-全氟烷基- $\beta$-杂芳基化 反应

Scheme 48 Metal-free $\alpha$-perfluoroalkyl- $\beta$-heteroarylation of unactived alkenes

弱相互作用实现了优秀的区域选择性和化学选择性控 制. 在此工作基础上, 储玲玲课题组 ${ }^{[79]}$ 又报道了镍催化 烯烃与氟烷基碘和芳基溴化物的三组分不对称 1,2-烷基 芳基化反应，这是金属催化烯烃三组分不对称双官能团 化反应的突破。该方法从简单易得的底物出发，反应条 件温和(室温), 以中等至优秀的收率和优异的对映选择 性快速高效地构建了一系列手性 $\beta$-氟烷基芳基烷烃，为 实现烯烃的多组分不对称转化提供了新的思路(Scheme 49).

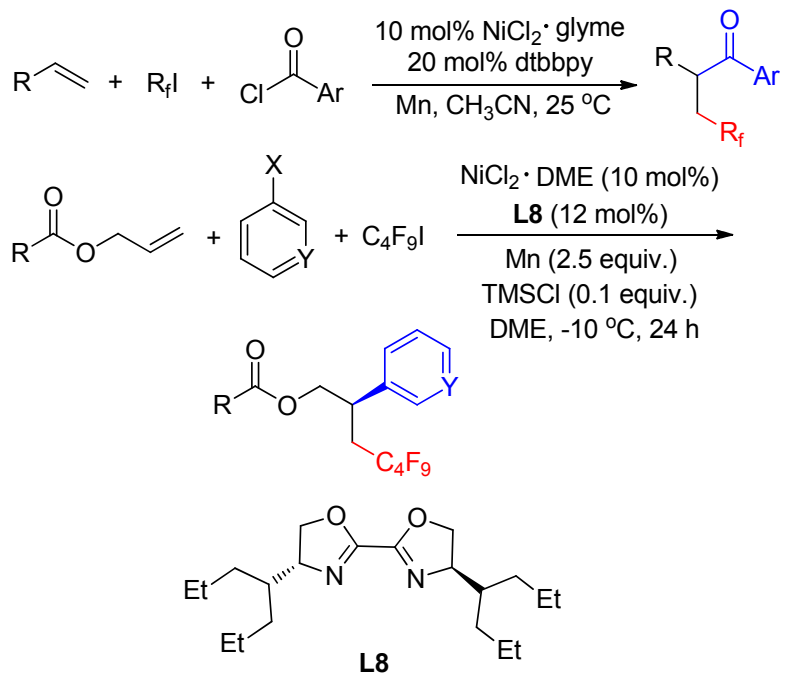

图式 49 镍催化烯烃的双官能团化反应

Scheme 49 Ni-catalyzed difunctionalization of alkenes

2019 年，鲍红丽等 ${ }^{[80}$ 报道了分子间的叠氮氟烷基 化反应，反应具有良好的底物普适性，烯烃和炔烃都以 中等及以上的产率得到了相应的产物。该反应所用的铁 催化剂价格便宜且毒性低. 这一反应已被成功地用于构 建各种有价值的结构骨架，包括许多氨基酸前体和氟烷 基乙烯基叠氮化物，其中乙烯基叠氮化合物(1-叠氮烯 烃)是有机合成中用途广泛的化合物，已被用于合成多 种具有生物活性的生物碱和杂环化合物. 鲍红丽等重点 探索了杂环化合物的合成，发现在 $120{ }^{\circ} \mathrm{C}$ 时，乙烯基叠 氮化合物可以在甲苯中高收率地转化为 $2 H$-唤丙啶，进 
一步说明了该方法在合成中的价值(Scheme 50).

$$
\begin{aligned}
& \underset{\mathrm{Ar}}{=}+\mathrm{R}_{\mathrm{f}}-\mathrm{I} \underset{\substack{\mathrm{TMSN}(1.4 \sim 2.0 \text { equiv. }) \\
\operatorname{TBPB}(2 \text { equiv. })}}{\mathrm{Fe}(\mathrm{OTf})_{2}(5 \text { mol\% })} \\
& \text { DME, r.t. }
\end{aligned}
$$

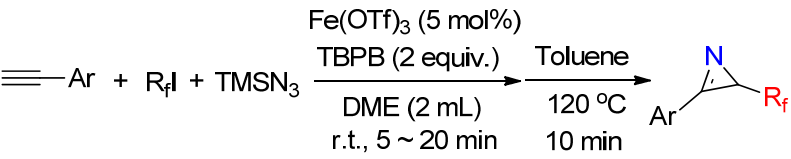

图式 50 铁催化烯烃与炔烃的氮全氟烷基化反应 Scheme 50 Pd-catalyzed nitrogenperfluoroalkylation of alkenes and alkynes

同年, 该课题组 ${ }^{[81]}$ 报道了铜催化的 1,3-烯炔的 1,4烷基氰化、1,4-氟烷基氰化和 1,4-磺酰胺氢化反应，生成 多取代的丙二烯, 这是天然产物中的重要结构组成, 也 是合成复杂分子的关键中间体，其可以很容易地转化为 含氟的乙烯基氰化物、内酯、二烯烃酰胺和吡啶等. 该 反应具有广阔的底物范围和良好的官能团耐受性, 反应 中过氧化双月桂酰(LPO)氧化剂的添加是 1,4-氟烷基氰 化反应的关键(Scheme 51).

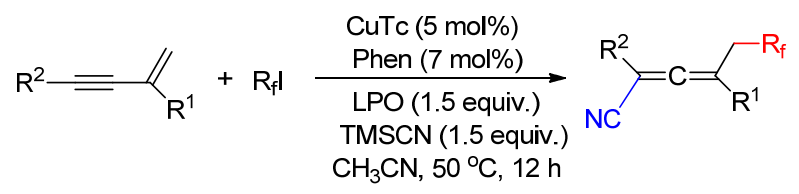

图式 51 铜催化 1,3-烯炔的双官能团化反应

Scheme $51 \mathrm{Cu}$-catalyzed difunctionalization of 1,3-enynes

含 $\mathrm{N}$ 杂环化合物是药物分子中最重要的结构单元 之一. 2018 年, Loh 等 $^{[82]}$ 开发了一种无金属的可见光氧 化还原催化的三组分 $[3+2+1]$ 环化反应，从易得的硅 烯醇醚、脒和氟烷基卤化物出发, 高效地合成了一系列 氟烷基嘧啶衍生物. 该反应对环境友好, 条件温和, 同 时具有高度的区域选择性和广泛的官能团耐受性, 进一 步扩大了这种转变的适用性, 为构建具有药用和生物活 性的有机含氟嘧啶类化合物提供了新的合成策略. 值得 注意的是, 利用三异丙基硅烯醇醚可以显著提高反应收 率，说明硅保护基团的相对稳定性和适当的空间位阻有 利于反应的进行. 此外, 直接用酮作为烯醇硅烷前体的 一锅法也获得了较好的合成收率(Scheme 52).

饱和 $\mathrm{N}$-杂环化合物, 特别是噁唑烷类化合物, 常常 存在于药物和生物活性分子中 ${ }^{[83-84]}$, 并作为手性催化剂 广泛应用于不对称合成, 引起了学术界和工业界的广泛 关注. 然而, 传统的方法中很少涉及含氟啞唑烷类化合 物的合成, 这些噁唑烷类化合物因含有氟原子而可能表 现出更好的生物和药物活性. 因此, 快速合成具有全取

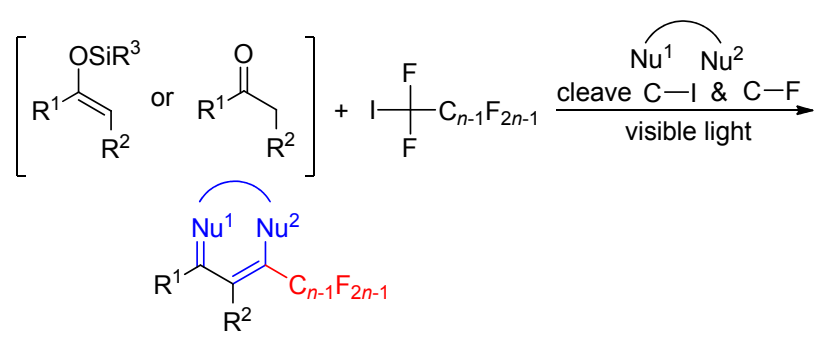

图式 52 光催化的 $[3+2+1]$ 成环反应

Scheme $52[3+2+1]$-Annulation using photoredox catalysis

代碳立体中心的啞唑烷类含氟砌块的方法将具有重要 的应用价值和良好的发展前景. 2019 年，沈志良等 ${ }^{[85}$ 报 道了一种可见光氧化还原催化的三组分反应，它可以将 易得的硅烯醇醚、氟烷基卤化物和手性氨基醇偶联在一 起，在无金属条件下以高度的区域选择性和非对映体选 择性合成 C-2-氟烷基噁唑烷，并显示出广泛的官能团耐 受性，这是饱和 $\mathrm{N}$-杂环化合物的一个有效合成方法. 此 外，直接用酮作为烯醇硅烷前体的一锅法也获得了较好 的合成收率. 初步的机理研究表明, 该反应可能通过形 成关键中间体氟取代的烯酮自由基反应途径进行 (Scheme 53).

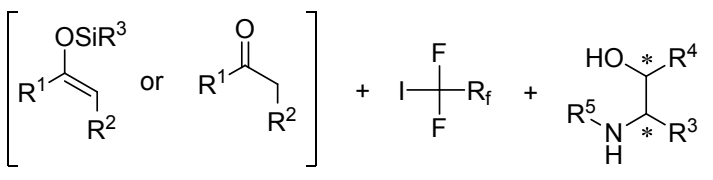

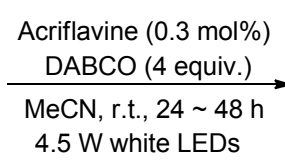

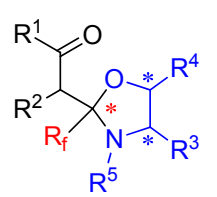

图式 53 光催化硅烯醇醚的全氟烷基化反应 Scheme 53 Perfluoroalkylation of Triisopropylsilane using photoredox catalysis

近年来, 紫外光催化的氧化还原反应在有机合成特 别是自由基偶联反应中得到了广泛的应用 ${ }^{[86]}$, 相比之 下, 铜催化剂在光氧化还原有机转化中的应用有限 ${ }^{[87]}$. 2017 年，王锐等 ${ }^{[88}$ 报道了光诱导下铜催化烯烃的氰基 氟烷基化反应. 该反应条件温和，直接使用氟烷基碘化 物作为氟烷基化试剂，与 Togni 和 Umemoto's 试剂相比, 价格便宜且更加安全, 此外, 除 $\mathrm{CF}_{3}$ 外还可以高效率地 引入多种氟烷基, 如 $\mathrm{C}_{4} \mathrm{~F}_{9} 、 \mathrm{C}_{6} \mathrm{~F}_{13} 、 \mathrm{C}_{8} \mathrm{~F}_{17}$ 和 $\mathrm{CF}_{2} \mathrm{CO}_{2} \mathrm{Et}$ 等. 然而, 外消旋产物的生成和致癌 UVC (ultra violet cradiation)光 $(254 \mathrm{~nm})$ 的使用, 外消旋产物的生成, 致癌 UVC (ultra violet cradiation)光(254 $\mathrm{nm}$ )和石英反应器 （也就是石英质或用高度石英化的 $\mathrm{SiO}_{2}$ 材质制成的反应 器, 特点是硬度高、耐高温、透明度好、化学惰性, 但 也缺乏延展性、易碎）的使用，都限制了该反应的应用 (Scheme 54). 


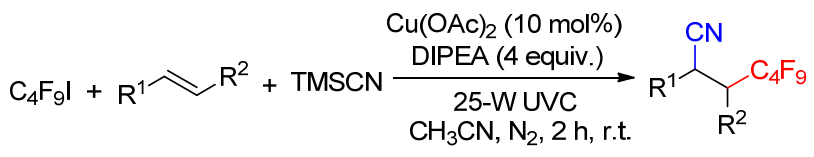

图式 54 铜催化烯烃的三组分氰基化氟烷基化反应 Scheme $54 \mathrm{Cu}$-catalyzed three components cyanofluoroalkylation of alkenes

随后，该课题组继续铜催化的光氧化还原反应的研 究，报道了 ${ }^{[89]}$ 光诱导下铜催化烯烃的叠氮氟烷基化反 应，同样在紫外光下用氟烷基碘化物作为氟烷基化试 剂, 对三氟甲基、二氟烷基 $\left(\mathrm{CF}_{2} \mathrm{CO}_{2} \mathrm{Et}\right)$ 和全氟烷基基团 的引入都很有效, 但脂肪族烯烃的双官能团化无法实 现. 值得注意的是, 雌酚酮衍生烯烃能够以良好的收率 和高非对映选择性得到目标产物, 此外, 用 $\mathrm{LiAlH}_{4}$ 还原 叠氮氟烷基化产物，以 $82 \%$ 的分离收率得到具有生物活 性的氟烷基取代胺(Scheme 55).

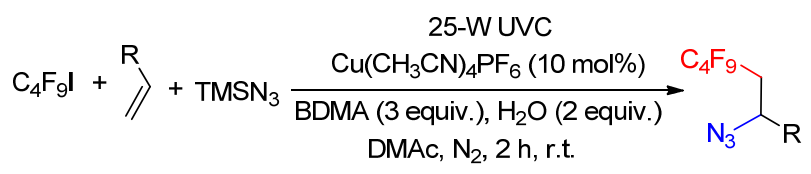

图式 55 铜催化烯烃的三组分叠氮氟烷基化反应

Scheme $55 \mathrm{Cu}$-catalyzed three components azidofluoroalkylation of alkenes

2019 年, 该课题组 ${ }^{[90]}$ 又报道了铜催化烯烃的光氧 化还原对映选择性氰基氟烷基化反应，其中催化剂 CuI 起到双重作用, 不仅是光氧化还原的增敏剂, 而且是不 对称转化的手性催化剂. 该反应底物范围广泛, 多种氟 烷基碘化物均具有良好的产率和对映选择性，促进了金 属催化剂的应用, 更重要的是使用温和的光源(LED), 在实验室标准玻璃器血即可反应, 使得该反应应用性更 强(Scheme 56).

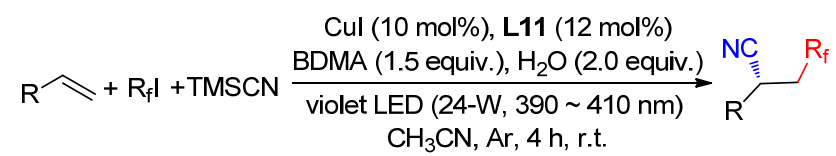

图式 56 铜催化烯烃的光氧化还原不对称氰基氟烷基化反应 Scheme $56 \mathrm{Cu}$-catalyzed photoredox asymmetric cyanofluoroalkylation of alkenes

\section{2 炔烃的三组分全氟烷基化反应}

2015 年, Nevado 等 ${ }^{[91]}$ 报道了钯催化的炔烃与全氟 烷基碘化物和芳基硼酸的三组分芳基全氟烷基化反应. 该反应同时形成两个新的碳碳键, 一步获得三取代的全 氟烷基烯烃, 突破了经典的多步反应过程(首先是全氟 烷基碘加成反应, 然后是钯催化的交叉偶联反应), 具 有高度的区域选择性和立体选择性, 反应操作简单, 同 时具有广泛的底物范围和良好的官能团耐受性. 值得注
意的是, 所有的底物都得到单一的 $E$ 型异构体，且该反 应条件仅适用于末端炔烃(Scheme 57).

$$
\equiv \mathrm{R}^{1}+\mathrm{R}^{2}-\mathrm{B}(\mathrm{OH})_{2}+\mathrm{R}_{\mathrm{f}}-\mathrm{I} \frac{\mathrm{PdCl}_{2}\left(\mathrm{PPh}_{3}\right)_{2}(4 \mathrm{~mol} \%)}{\mathrm{DCM} / \mathrm{H}_{2} \mathrm{O}, 50^{\circ} \mathrm{C}, 12 \mathrm{~h}} \underset{\mathrm{R}^{1}}{\mathrm{R}_{\mathrm{f}}^{2}} \mathrm{R}_{\mathrm{f}}
$$

图式 57 钯催化末端炔烃的芳基全氟烷基化反应 Scheme 57 Pd-catalyzed arylperfluoroalkylation of terminal alkynes

2017 年, Nevado 等 ${ }^{[92]}$ 在之前末端炔烃芳基全氟烷 基化的基础上又发展了非末端炔烃的芳基全氟烷基化 反应. 该反应以便宜易得的碘代全氟烷烃作为氟烷基化 试剂，在高度区域选择和立体选择控制的条件下得到各 种有价值的四取代的全氟烷基化烯烃(Scheme 58).

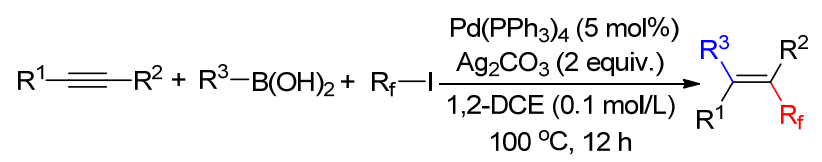

图式 58 钯催化炔烃的芳基全氟烷基化反应

Scheme 58 Pd-catalyzed arylperfluoroalkylation of alkynes

2016 年, Chaładaj 等 ${ }^{[93]}$ 报道了钯催化的炔烃与碘代 全氟烷烃和芳基硼酸的芳基全氟烷基化反应. 该反应具 有高度立体选择性和区域选择性，为三取代和四取代的 全氟烷基化烯烃的合成提供了新方法. 同时该反应条件 温和, 产物收率高, 更为重要的是其底物范围是迄今为 止最广泛的，末端炔烃、分子内炔烃以及杂环芳基硼酸 都可作为底物(Scheme 59).

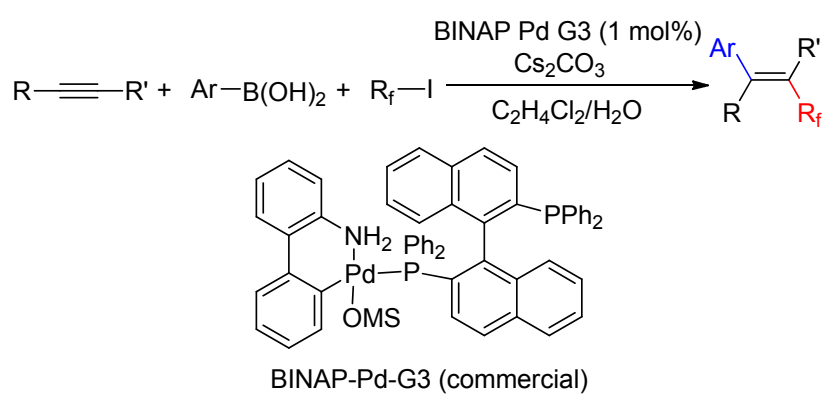

图式 59 钯催化炔烃的芳基全氟烷基化反应 Scheme 59 Pd-catalyzed arylperfluoroalkylation of alkynes

2019 年, Chaładaj 等 ${ }^{[94]}$ 又报道了一种钯催化的三组 分串联反应，包括炔烃的碘全氟烷基化反应、喼全氟烷 基化反应和芳基全氟烷基化反应. 该反应通过控制反应 条件可以实现三种反应产物的选择性控制，即在无水条 件下可得到碘化全氟烷基化烯烃，在有水条件下，再通 过程序升温可将硼酯化全氟烷基化乙烯转化为芳基化 全氟烷基化乙烯. 该反应中产物收率高，具有良好的区 域选择性、立体选择性以及官能团耐受性. 在多组分反 
应的背景下, 这种可控的多样性导向催化的进一步研究 还有待探索(Scheme 60).

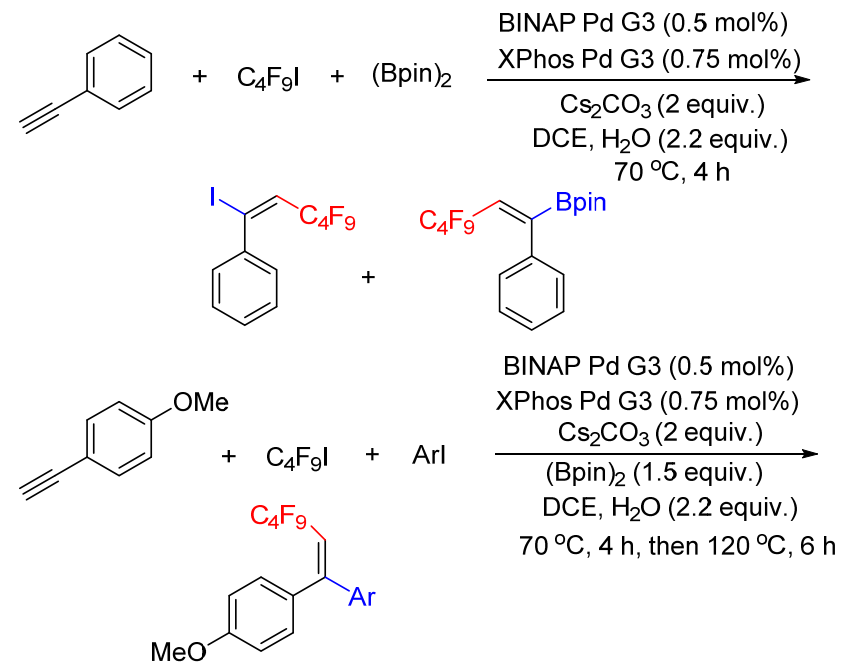

图式 60 钯催化炔烃的双官能团化反应 Scheme 60 Pd-catalyzed difunctionalization of alkynes

\section{4 三组分参与的单氟烷基化反应}

单氟烷基化尽管没有三氟以及全氟烷基化应用广 泛，但是该方法可以一步同时引入氟原子和其它基团, 比直接氟化法在步骤经济性上更有优势. 单个 $\mathrm{C}-\mathrm{F}$ 键 取代 $\mathrm{C}-\mathrm{H}$ 或者 $\mathrm{C}-\mathrm{O}$ 键后, 尽管分子整体的体积不会 发生太大的改变, 但是可以改变相邻基团的酸碱性以及 分子的优势构象, 从而影响化合物的生物利用度或者与 靶标蛋白的相互结合能力, 这对设计药物分子具有重要 意义 ${ }^{[95]}$. 鉴于很多药物以及生物活性分子中含有氟代 的三级或四级碳, 该合成方法作为直接氟化法的一个补 充，有望在药物分子设计中得到应用(Scheme 61).

2019 年, 卿凤翎课题组 ${ }^{[96]}$ 以氟碘甲烷 $\left(\mathrm{CH}_{2} \mathrm{FI}\right)$ 为氟 甲基化试剂, 发展了铜催化烯烃区域选择性的硼化氟甲 基化反应. 该反应底物普适性较广, 且得到的嗍化氟甲 基化产物中的硼酸酯可转化为其他的基团. 在不同的反 应条件下, 苯乙烯的嗍化氟甲基化产物以较高的产率转 化为一系列亚甲基插入、烯基化、杂芳基化、羟化、溴 化、碘化和氟化产物. 这些新生成的含 $\mathrm{CH}_{2} \mathrm{~F}$ 化合物以 前基本没有报道过, 它们有望作为中间体应用于有机合 成和药物研发(Scheme 62).

\section{5 三组分参与的氟化反应}

氟在农用化学品和医药中的重要性的日益增加, 促 使人们研究在温和条件下发生氟化反应的新方法, 特别 是不饱和碳碳键的氟化, 已成为形成 $C\left(\mathrm{sp}^{3}\right)-\mathrm{F}$ 键的有

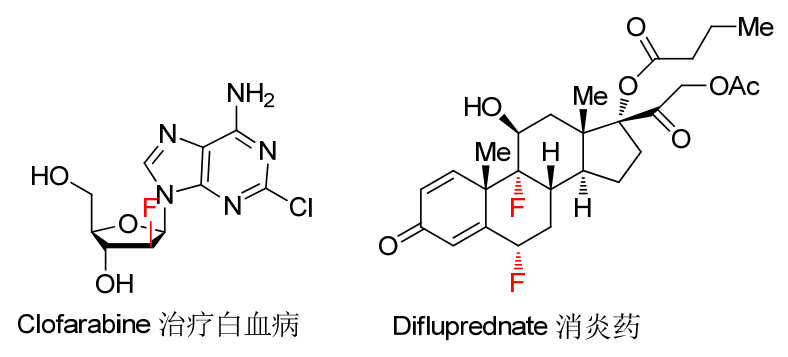

图式 61 含有氟代三级碳和四级碳的药物分子

Scheme 61 Drug molecules ccontaining fluorinated tertiary and quaternary carbons

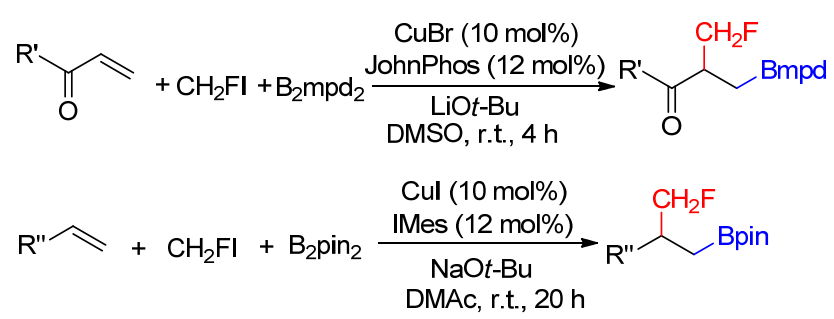

图式 62 铜催化烯烃的嗍单氟甲基化反应

Scheme 62 Cu-catalyzed boronmonofluoromethylation of alkene

力工具. 2013 年, 李超忠课题组 ${ }^{[97]}$ 报道了银催化的未活 化烯烃与亚磷酸二乙酯和选择性氟化试剂的三组分膦 氟化反应，方便、高效地合成了 $\beta$-氟化膦酸酯类化合物. 该反应在温和的水介质条件下进行，具有底物范围广、 官能团相容性广、立体选择性好等特点, 成为形成 $\mathrm{C}\left(\mathrm{sp}^{3}\right)-\mathrm{F}$ 键的有力工具 (Scheme 63).

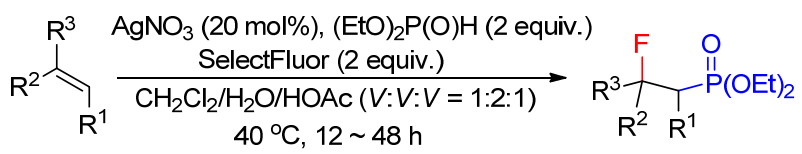

图式 63 银催化未活化烯烃的膦氟化反应 Scheme 63 Silver-catalyzed phosphonofluorination of unactivated alkenes

同年, 刘国生课题组 ${ }^{[98]}$ 利用温和的亲电氟化试剂 NFSI，开发了一种新型钯催化的芳基乙烯的酯基单氟 烷基化反应. 该反应为一系列 $\alpha$-单氟甲基茮基羧酸酯开 辟了一条有效的合成途径. 同时刘国生等直接在反应中 加入吡啶(pyridine)和甲醇, 使 $\alpha$-单氟甲基芐基羧酸酯进 一步水解为相应的醇, 为此反应的进一步应用提供了条 件. 但是该方法用分子内烯烃作为底物时, 非对映选择 性较差(Scheme 64).

\section{6 四组分参与的氟烷基化反应}

\section{1 烯烃的四组分氟烷基化反应}

2013 年, Akita 等 ${ }^{[99]}$ 报道了通过光氧化还原催化烯 烃的氨基三氟甲基化反应，在室温条件下，以良好的产 


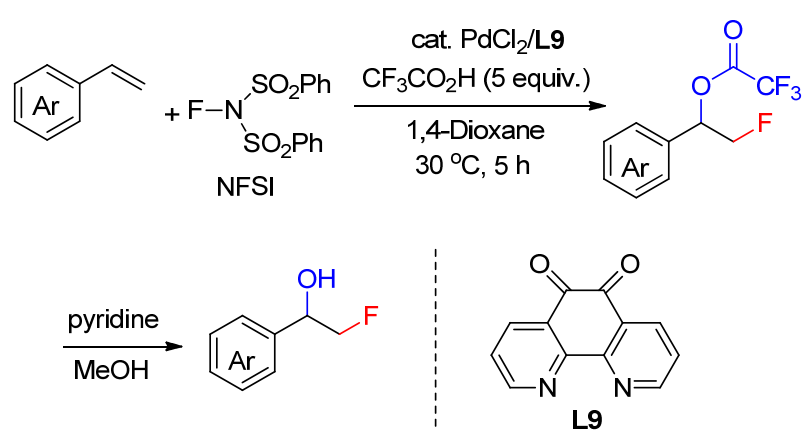

图式 64 钯催化芳基乙烯的酯基单氟烷基化反应 Scheme 64 Pd-catalyzed estermonofluoroalkylation of arylethylene

物收率和较高的区域选择性一步获得 1,1,1-三氟-3-酰氨 基丙烷衍生物, 它们是含 $\mathrm{CF}_{3}$ 的生物活性化合物中的重 要结构基序. 此外, 该反应可以用于天然产物或药物的 后三氟甲基化反应(late-stage aminotrifluoromethylation), 合成一系列含三氟甲基的类药物分子, 为开发含氟药物 提供方便和有效的方法. 作者已将该反应应用于乙烯雌 酮以及类固醇、氨基酸等复杂小分子的氨基三氟甲基化 反应, 且对于端烯和内烯都有很好的底物兼容性 (Scheme 65).

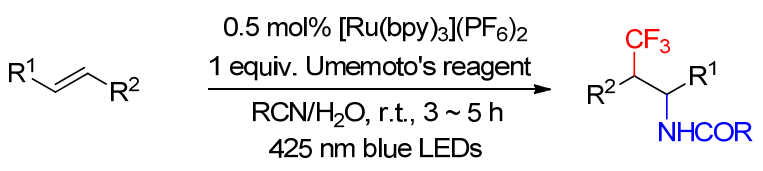

图式 65 光催化烯烃的氨基三氟甲基化反应

Scheme 65 Aminotrifluoromethylation of alkenes using photoredox catalysis

含全氟烷基化合物通常具有较高的代谢稳定性、溶 解度、亲脂性、生物利用度和生物活性, 这促进了学者 们对全氟烷基化反应的广泛关注. 已有的文献报道中, 在非氧化条件下全氟烷基卤化物自由基加成烯烃是构 建全氟化合物最有效的方法之一. 相比之下, 关于全氟 烷基卤化物与烯烃氧化偶联的文献报道很少. 2015 年, 万小兵等 ${ }^{[100]}$ 报道了以三乙烯二胺为配体, $\mathrm{Co}(\mathrm{acac})_{2}$ 为 催化剂的苯乙烯的氟烷基化反应和 KornblumDeLaMare 反应, 通过多组分自由基过程, 合成了(Z)- $\beta$ 全氟烷基烯丙酮, 这一类结构是有机合成化学中的重要 中间体. 该氧化反应具有高度的化学选择性和立体选择 性, 但底物范围较窄(Scheme 66).

\section{2 炔烃的四组分二氟烷基化反应}

钯作为催化剂是在多组分羰基化反应中构建羧酸 及其衍生物(如酯和酰胺)的最直接途径. 2016 年, 梁永 民等 ${ }^{[101]}$ 报道了一种以碘二氟乙酸乙酯为 $\mathrm{CF}_{2}$ 自由基前 体的钯催化的四组分羰基二氟烷基化反应, 在 $\mathrm{CO}$ 气氛

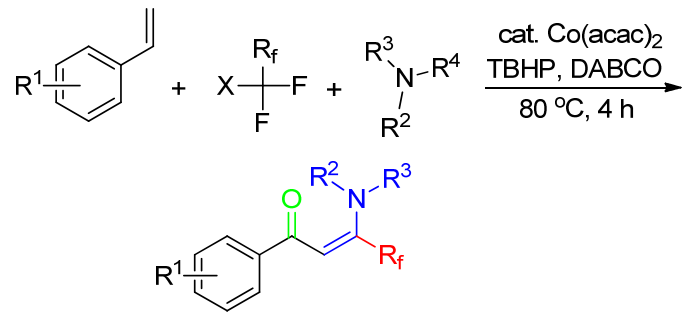

图式 66 钴催化烯烃的氟烷基化反应和 Kornblum-DeLaMare 反应

Scheme 66 Co-catalyzed fluoroalkylation and KornblumDeLaMare reaction of styrenes

下，通过一步反应，高区域选择性地构建两个碳碳键和 一个碳氧键. 此外, 与传统的 RCONu 的合成路线相比, 该多组分反应以简单易得的起始原料进行，避免了繁琐 的多步合成，缩减了合成时间。同时各种炔烃和亲核试 剂都适用于该反应，更加证明了该反应体系的应用前 景, 使用一级醇和二级醇时, 都能得到满意的结果. 重 要的是, 一些酚类物质也适合这种转化，以中等产率获 得了相应的产物. 最后, 杂胺也可以作为亲核试剂, 进 行底物拓展, 单取代芳基胺和烷基胺在转化过程中得到 了良好的 $E / Z$ 产物比. 目前正在将这种化学反应进一步 扩展到其他亲核试剂中(Scheme 67).

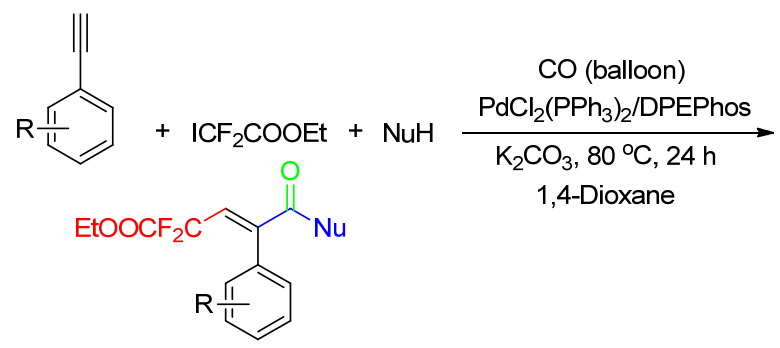

图式 67 钯催化炔烃的羰基二氟烷基化反应

Scheme 67 Pd-catalyzed carbonyldifluoroalkylation of alkynes

$\alpha, \beta$-不饱和酮是天然产物中的一种重要骨架，广泛 存在于生物活性化合物中, 具有药理和生物学性质. 2017 年, 梁永民课题组又报道了 ${ }^{[102]}$ 钯催化的四组分羰 基二氟烷基化反应，实现了四组分羰基全氟烷基化反 应，在非常温和的条件下合成了二氟烷基/全氟烷基烯 酮类化合物. 与传统过渡金属催化的羰基偶合通常需要 高温且官能团容忍性差相比，该反应具有效率高、官能 团相容性好及底物范围广泛等特点, 为其在有机合成中 的应用提供了优势. 值得注意的是, $\mathrm{CsF}$ 在反应中起着 至关重要的作用, 能大大加快反应速率(Scheme 68).

\section{7 结论与展望}

从上述的讨论可以看出, 多组分参与的氟烷基化反 应已经引起了有机化学研究者们的广泛重视并且取得 


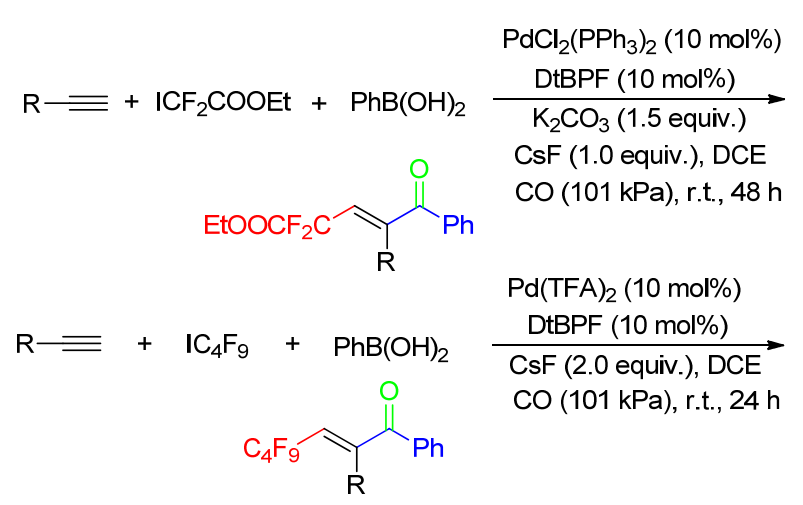

图式 68 钯催化炔烃的羰基二氟烷基化/全氟烷基化反应 Scheme 68 Pd-catalyzed carbonyldifluoroalkylation/carbonylperfluoroalkylation of alkynes

了重要的进展, 各种烯烃和炔烃的氟烷基化反应都被广 泛报道. 笔者认为主要有以下原因: (1)向有机分子引入 氟原子或含氟基团是有机氟化学研究的永恒课题; (2)烯 烃和炔烃作为常见底物, 通过多组分参与的氟烷基化反 应，可以一步合成各种含有生物活性或药物活性的产 物; (3)多组分参与的氟烷基化反应为一些金属催化剂和 手性配体的发展提供了更好的方法.

随着研究的深入, 多组分参与的氟烷基化反应仍面 临很多问题和挑战: (1)对于金属催化的多组分氟烷基化 反应，催化剂的回收及循环利用问题仍需要更多的研 究; (2)尽管近年多组分参与的氟烷基化反应取得重要进 展, 多组分参与的氟烷基化反应仍将是有机氟化学的重 要研究方向, 特别是发展无金属催化的多组分氟烷基化 反应，可以降低反应成本，同时更符合绿色化学的要求; (3)含氟手性化合物在药物研发中起到重要作用, 因此 发展不对称反应构建 C-F 键和 C-CFXY 的方法将是多 组分参与的氟烷基化反应的重要研究方向; (4)多组分参 与的氟烷基化反应的开发应用较少, 尤其是在药物分子 和生物活性分子方面的应用还有待探索; (5)炔烃的多组 分氟烷基化反应方面需要展开更广泛的研究; (6)目前, 多组分参与的氟烷基化反应还缺乏系统的理论指导, 相 关的动力学研究以及对反应历程的理解方面还有待进 一步的深入研究; (7)与三氟甲基化相比, 多组分参与的 二氟烷基化以及单氟烷基化的方法比较有限, 相关报道 较少; (8)多组分参与的三氟甲基化反应已经取得了显著 突破, 目前存在的主要问题是三氟甲基化试剂相对较 贵, 某些三氟甲基取代的化合物的合成仍然较难, 所以 发展新型的三氟甲基化试剂, 扩大反应底物范围仍是当 前的一项重要挑战.

\section{References}

[1] (a) Xu, J.; Liu, X.; Fu, Y. Tetrahedron Lett. 2014, 55, 585.

(b) Wang, G.; He, X.; Dai, J.; Xu, H. Chin. J. Org. Chem. 2014, 34, 837 (in Chinese).
(王光祖, 赫侠平, 戴建军, 许华建, 有机化学, 2014, 34, 837.) (c) Zhang, J.; Jin, C.; Zhang, Y. Chin. J. Org. Chem. 2014, 34, 662 (in Chinese).

(张雯, 金传飞, 张英俊, 有机化学, 2014, 34, 662.)

(d) Merino, E.; Nevado, C. Chem. Soc. Rev. 2014, 43, 6598.

(e) Chu, L.; Qing, F. L. Acc. Chem. Res. 2014, 47, 1513

[2] Qing, F. L. Chin. J. Org. Chem. 2012, 32, 815 (in Chinese). (卿凤翎, 有机化学, 2012, 32, 815.)

[3] (a) Schlosser, M. Angew. Chem., Int. Ed. 2006, 45, 5432.

(b) Müller, K.; Faeh, C.; Diederich, F. Science 2007, 317, 1881.

(c) Purse, S.; Moore, P. R.; Swallow, S.; Gouverneur, V. Chem. Soc. Rev. 2008, 37, 320 .

(d) Kirk, K. L. Org. Process Res. Dev. 2008, 12, 305.

(e) Wang, J.; Liu, H. Chin. J. Org. Chem. 2011, 31, 1785 (in Chinese). (王江, 柳红, 有机化学, 2011, 31, 1785.)

[4] (a) An, L.; Tong, F. F.; Zhang, X. G. Acta Chim. Sinica 2018, 76, 977 (in Chinese).

(安伦, 童非非, 张新刚, 化学学报, 2018, 76, 977.)

(b) He, X.; Gao, X.; Zhang, X. G. Chin. J. Chem. 2018, 36, 1059.

(c) Xie, Q. Q.; Hu, J. B. Chin. J. Chem. 2020, 38, 202.

[5] (a) Ni, C. F.; Zhu, L. G.; Hu, J. B. Acta Chim. Sinica 2015, 73, 90 (in Chinese).

(倪传法, 朱林桂, 胡金波, 化学学报, 2015, 73, 90.)

(b) Lü, C. P.; Shen, Q. L.; Liu, D. Chin. J. Org. Chem. 2012, 32, 1380 (in Chinese).

(吕翠萍，沈其龙，刘丹，有机化学, 2012, 32, 1380.)

[6] (a) Erickson, J. A.; McLoughlin, J. I. J. Org. Chem. 1995, 60, 1626. (b) Narjes, F.; Koehler, K. F.; Koch, U.; Gerlach, B.; Colarusso, S.; Steinkühler, C.; Brunetti, M.; Altamura, S.; De Francesco, R.; Matassa, V. G. Chem. Lett. 2002, 12, 701.

(c) Xu, Y.; Qian, L.; Pontsler, A. V.; McIntyre, T. M.; Prestwich, G. D. Tetrahedron Lett. 2004, 60, 43.

(d) Purser, S.; Moore, P. R.; Swallow, S.; Gouverneur, V. Chem. Soc. Rev. 2008, 37, 320.

(e) Chowdhury, M. A.; Abdellatif, K. R. A.; Dong, Y.; Das, D.; Suresh, M. R.; Knaus, E. E. J. Med. Chem. 2009, 52, 1525.

[7] (a) Nguyen, J. D.; Tucker J. W.; Stephenson, C. R. J. J. Am. Chem. Soc. 2011, 133, 4160.

(b) Wallentin, C. J.; Nguyenand, J. D. C.; Stephenson, R. J. J. Am. Chem. Soc. 2012, 134, 8875.

[8] Arai, Y.; Tomita, R.; Ando, G.; Koike, T.; Akita, M. Chem.-Eur. J. 2016, 22, 1262.

[9] Lv, X. L.; Wang, C.; Wang, Q. L.; Shu, W. Org. Lett. 2019, 21, 56.

[10] Xu, R.; Cai, C. Chem. Commun. 2019, 55, 4383.

[11] Shu, W.; Merino, E.; Nevado, C. ACS Catal. 2018, 8, 6401.

[12] Deng, X. Y.; Lin, J. H.; Zheng, J.; Xiao, J. C. Chem. Commun. 2015, 51,8805 .

[13] Zhang, M.; Lin, J. H.; Xiao, J. C. Angew. Chem., Int. Ed. 2019, 58, 6079.

[14] Gu, J. W.; Min, Q. Q.; Yu, L. C.; Zhang, X. Angew. Chem., Int. Ed. 2016, 55,12270

[15] Xu, C.; Yang, Z. F.; An, L.; Zhang, X. G. ACS Catal. 2019, 9, 8224

[16] Zhang, K. F.; Bian, K. J.; Li, C.; Sheng, J.; Li, Y.; Wang, X. S. Angew. Chem., Int. Ed. 2019, 58, 5069.

[17] (a) Bunescu, A.; Wang, Q.; Zhu, J. Angew. Chem., Int. Ed. 2015, 54, 3132 .

(b) Ha, T. M.; Chatalova-Sazepin, C.; Wang, Q.; Zhu, J. Angew. Chem., Int. Ed. 2016, 55, 9249.

(c) Fan, J.-H.; Wei, W. T.;Zhou, M. B.; Song, R. J.; Li, J. H. Angew Chem., Int. Ed. 2014, 53, 6650.

(d) Ouyang, X. H.; Song, R. J.; Hu, M.; Yang, Y.; Li, J. H. Angew Chem., Int. Ed. 2016, 55, 3187.

(e) Liu, Y. Y.; Yang, X. H.;Song, R. J.; Luo, S.; Li, J. H. Nat. Commun. 2017, 8, 14720

(f) Zhou, S. F.; Li, D. P.; Liu, K.; Zou, J. P.; Asekun, O. T. J. Org. Chem. 2015, 80, 1214.

[18] Kong, W.; Yu, C.; An, H.; Song, Q. L. Org. Lett. 2018, 20, 4975. 
[19] (a) Ke, M.; Feng, Q.; Yang, K.; Song, Q. L. Org. Chem. Front. 2016, 3, 150 .

(b) Ke, M.; Song, Q. J. Org. Chem. 2016, 81, 3654

(c) Ke, M.; Song, Q. Adv. Synth. Catal. 2017, 359, 384.

(d) Ke, M.; Song, Q. Chem. Commun. 2017, 53, 2222.

(e) Fu, W.; Song, Q. Org. Lett. 2018, 20, 393.

[20] Chen, Y. J.; Li, L. K.; Ma, Y. Y.; Li, Z. P. J. Org. Chem. 2019, 84, 5328 .

[21] He, Y. T.; Wang, Q.; Li, L. H.; Liu, X. Y.; Xu, P. F.; Liang, Y. M. Org. Lett. 2015, 17, 5188.

[22] He, Y. T.; Li, L. H.; Wang, Q.; Wu, W.; Liang, Y. M. Org. Lett. 2016, $18,5158$.

[23] Zhang, P. B.; Ying, J. X.; Tang, G.; Zhao, Y. F. Org. Chem. Front. 2017, 4, 2054

[24] Liang, J. Q ; Huang, G. Z.; Peng, P.; Zhang, T.; Wu, J.; Wu, F. Adv. Synth. Catal. 2018, 360, 2221.

[25] (a) Suginome, M.; Yamamoto, A.; Murakami, M. J. Am. Chem. Soc. 2003, 125, 6358.

(b) Suginome, M.; Yamamoto, A.; Murakami, M. Angew. Chem., Int. Ed. 2005, 44, 2380 .

(c) Suginome, M.; Shirakura, M.; Yamamoto, A. J. Am. Chem. Soc. 2006, $128,14438$.

[26] (a) Yamamoto, A.; Suginome, M. J. Am. Chem. Soc. 2005, 127, 15706.

(b) Daini, M.; Yamamoto, A.; Suginome, M. J. Am. Chem. Soc. 2008, 130, 2918.

(c) Zhang, L.; Cheng, J.; Carry, B.; Hou, Z. J. Am. Chem. Soc. 2012, 134, 14314

(d) Alfaro, R.; Parra, A.; Alemán, J.;Ruano, J. L. G.; Tortosa, M. J. Am. Chem. Soc. 2012, 134, 15165 .

(e) Yoshida, H.; Kageyuki, I.; Takaki, K. Org. Lett. 2013, 15, 952.

(f) Zhou, Y.; You, W.; Smith, K. B.; Brown, M. K. Angew. Chem., Int. Ed. 2014, 53, 3475.

(g) Bidal, Y. D.; Lazreg, F.; Cazin, C. S. J. Am. Chem. Soc. 2014, 4, 1564 .

(h) Nakagawa, N.; Hatakeyama, T.; Nakamura, M. Chem.-Eur. J. 2015, 21, 4257.

(i) Bin, H. Y.; Wei, X.; Zi, J.; Zuo,Y. J.; Wang, T. C.; Zhong, C. M. ACS Catal. 2015, 5, 6670 .

(j) Kubota, K.; Iwamoto, H.; Yamamoto, E.; Ito, H. Org. Lett. 2015, 17,620 .

(k) Su, W.; Gong, T. J.; Zhang, Q.; Zhang, Q.; Xiao, B.; Fu, Y. ACS Catal. 2016, 6, 6417.

(1) Itoh, T.; Shimizu, Y.; Kanai, M. J. Am. Chem. Soc. 2016, 138, 7528.

(m) Mateos, J.; Rivera-Chao, E.; Fañanás-Mastral, M. ACS Catal. 2017, 7, 5340 .

(n) Han, J. T.; Yun, J. Org. Lett. 2018, 20, 2104.

[27] (a) Mannathan, S.; Jeganmohan, M.; Cheng, C. H. Angew. Chem., Int. Ed. 2009, 48, 2192.

(b) Okuno, Y.; Yamashita, M.; Nozaki, K. Angew. Chem., Int. Ed. 2011, 50,920

(c) Nagao, K.; Ohmiya, H.; Sawamura, M. J. Am. Chem. Soc. 2014, 136, 10605 .

(d) Yamazaki, A.; Nagao, K.; Lwai, T.; Ohmiya, H.; Sawamura, M. Angew. Chem., Int. Ed. 2018, 57, 3196.

(e) Roscales, S.; Csákÿ, A. G. Org. Lett. 2015, 17, 1605.

(f) Nogami, M.; Hirano, K.; Kanai, M.; Wang, C.; Saito, T.; Miyamoto, K.; Muranaka, A.;Uchiyama, M. J. Am. Chem. Soc. 2017, 139,12358

[28] Wang, S. F.; Zhang, J.; Kong, L. C.; Tan, Z.; Bai, Y. H.; Zhu, G. G. Org. Lett. 2018, 20, 5631.

[29] Guo, W. H.; Zhao, H. Y.; Luo, Z. J.; Zhang, S.; Zhang, X. G. ACS Catal. 2019, 9, 38.

[30] Yasu, Y.; Koike, T.; Akita, M. Angew. Chem., Int. Ed. 2012, 51, 9567.

[31] Li, Y.; Studer, A. Angew. Chem., Int. Ed. 2012, 51, 8221.

[32] Feng, C.; Loh, T.-P. Chem. Sci. 2012, 3, 3458.
[33] Carboni, A.; Dagousset, G.; Magnier, E.; Masson, G. Org. Lett. 2014, 16, 1240.

[34] (a) Sani, M.; Bruché, L.; Chiva, G.; Fustero, S.; Piera, J.;Volonterio, A.; Zanda, M. Angew. Chem., Int. Ed. 2003, 42, 2060.

(b) Ogu, K.; Matsumoto, S.; Akazome, M.; Ogura, K. Org. Lett. 2005, 7, 589 .

(c) Jakowiecki, J.; Loska, R.; Makosza, M. J. Org. Chem. 2008, 73, 5436.

(d) Fustero, S.; Chiva, G.; Piera, J.; Sanz-Cervera, J. F.;Volonterio, A.; Zanda, M.; Ramirez de Arellano, C. J. Org. Chem. 2009, 74, 3122 .

(e) Benhaim, C.; Bouchard, L.; Pelletier, G.; Sellstedt, J.; Kristofova, L.; Daigneault, S. Org. Lett. 2010, 12, 2008.

[35] Huang, L.; Zheng, S. C.; Tan, B.; Liu, X. Y. Org. Lett. 2015, 17, 1589.

[36] (a) Langlois, B. R.; Laurent, E.; Roidot, N. Tetrahedron Lett. 1991, 32,7525 .

(b) Langlois, B. R.; Laurent, E.; Roidot, N. Tetrahedron Lett. 1992, 33, 1291.

[37] Yang, Y. D.; Iwamoto, K.; Tokunaga, E.; Shibata, N. Chem. Commun. 2013, 49, 5510 .

[38] Ji, Y.; Brueckl, T.; Baxter, R. D.; Seiple, I. B.; Su, S.; Blackmond, D. G.; Baran, P. S. Proc. Natl. Acad. Sci. U. S. A. 2011, 108, 14411.

[39] Ye, Y.; Kunzi, S.; Sanford, M. S. Org. Lett. 2012, 14, 4979.

[40] Jiang, X. Y.; Qing, F. L. Angew. Chem., Int. Ed. 2013, 52, 14177.

[41] Wang, F.; Qi, X.; Liang, Z.; Chen, P.; Liu, G. S. Angew. Chem., Int. Ed. 2014, 53, 1881.

[42] Dagousset, G.; Carboni, A.; Magnier, E.; Masson, G. Org. Lett. 2014, 16, 4340.

[43] Yang, X.; Sun, Y. W.; Zhang, G. Z. Org. Lett. 2018, 20, 6250.

[44] Li, Q.; Wang, W.; Berst, K. B.; Claiborne, A.; Hasvold, L.; Raye, K. M.; Nilius, T. A.; Shen, L. L.; Flamm, R.; Alder, J.; Marsh, K. Crowell, D.; Chu, D. T. W.; Plattner, J. J. Bioorg. Med. Chem. Lett. 1998, 8, 1953.

[45] Zhu, C. L.; Wang, C.; Qin, Q. X.; Yruegas, S.; Martin, C. D.; Xu, H. ACS Catal. 2018, 8, 12317.

[46] Liang, Z.; Wang, F.; Chen, P.; Liu, G. Org. Lett. 2015, 17, 2438

[47] Grishchuk, B. D.; Prodanchuk, N. G.; Sinchenko, V. G.; Gorbovoi, P. M.; Kudrik, E. Y. Pharm. Chem. J. 1994, 28, 657.

[48] Szajnman, S. H.; Yan, W.; Bailey, B. N.; Docampo, R.; Elhalem, E.; Rodriguez, J. B. J. Med. Chem. 2000, 43, 1826.

[49] Kong, W.; An, H.; Song, Q. Chem Commun. 2017, 53, 8968.

[50] (a) Murdoch, D.; Keam, S. Drugs 2005, 65, 2379.

(b) Ozoe, Y.; Ishikawa, S.; Tomiyama, S.; Ozoe, F.; Kozaki, T.; Scott, J. G. J. Am. Chem. Soc. 2007, 948, 39.

[51] He, Y. T.; Li, L. H.; Yang, Y. F.; Zhou, Z. Z.; Hua, H. L.; Liu, X. Y.; Liang, Y. M. Org. Lett. 2014, 16, 270.

[52] Ichenko, N. O.; Janson, P. G.; Szabó, K. J. J. Org. Chem. 2013, 78, 11087.

[53] Liang, Z.; Wang, F.; Chen, P.; Liu, G. J. Fluorine Chem. 2014, 167, 55.

[54] Wang, F.; Wang, D.; Wan, X.; Wu, L.; Chen, P.; Liu, G. J. Am. Chem. Soc. 2016, 138, 15547.

[55] Zhang, Z. Q.; Meng, X. Y.; Sheng, J.; Lan, Q.; Wang, X. S. Org. Lett. 2019, 21, 8256 .

[56] Jarrige, L.; Carboni, A.; Dagousset, G.; Levitre, G.; Magnier, E.; Masson, G. Org. Lett. 2016, 18, 2906.

[57] Morán-Ramallal, R.; Gotor-Fernández, V.; Laborda, P.; Sayago, F. J.; Cativiela, C.; Gotor, V. Org. Lett. 2012, 14, 1696.

[58] Zhu, Y.; Tian, J. L.; Gu, X. F.; Wang, Y. H. J. Org. Chem. 2018, 83 , 13267.

[59] (a) Ghera, E.; Shoua, S. Tetrahedron Lett. 1974, 15, 3843.

(b) Zhao, B.; Yuan, W.; Du, H.; Shi, Y. Org. Lett. 2007, 9, 4943.

(c) Taniguchi, T.; Sugiura, Y.; Zaimoku, H.; Ishibashi, H. Angew. Chem., Int. Ed. 2010, 49, 10154 .

(d) Taniguchi, T.; Idota, A.; Yokoyama, S.; Ishibashi, H. Tetrahedron Lett. 2011, 52, 4768.

(e) Taniguchi, T.; Zaimoku, H.; Ishibashi, H. Chem.-Eur. J. 2011, 
17, 4307.

(f) Zhang, H.; Song, Y.; Zhao, J.; Zhang, J.; Zhang, Q. Angew. Chem., Int. Ed. 2014, 53, 11079.

(g) Lu, D. F.; Zhu, C. L.; Jia, Z. X.; Xu, H. J. Am. Chem. Soc. 2014, 136, 13186.

(h) Zhu, R.; Buchwald, S. L. J. Am. Chem. Soc. 2015, 137, 8069.

(i) Sun, X.; Li, X.; Song, S.; Zhu, Y.; Liang, Y. F.; Jiao, N. J. Am. Chem. Soc. 2015, 137, 6059

(j) Miner, M. R.; Woerpel, K. A. Eur. J. Org. Chem. 2016, 2016, 1860 .

(k) Lu, D. F.; Zhu, C. L.; Sears, J. D.; Xu, H. J. Am. Chem. Soc. 2016, 138,11360

(1) Cheng, J. K.; Loh, T. P. J. Am. Chem. Soc. 2015, 137, 42.

(m) Andia, A. A.; Miner, M. R.; Woerpel, K. A. Org. Lett. 2015, 17, 2704.

[60] (a) Alameda-Angulo, C.; Quiclet-Sire, B.; Zard, S. Z. Tetrahedron Lett. 2006, 47, 913.

(b) Soueni, A. E.; Tedder, J. M.; Walton, J. C. J. Fluorine Chem. 1981, 17, 51 .

(c) Poutsma, M.; Ibarbia, P. J. Org. Chem. 1970, 35, 4038.

[61] Wang, F.; Wang, D. H.; Zhou, Yu.; Liang, L.; Lu, R. H.; Chen, P. H.; Lin, Z. Y.; Liu, G. S. Angew. Chem., Int. Ed. 2018, 57, 7140.

[62] Wang, F.; Wang, D.; Mu, X.; Chen, P.; Liu, G. J. Am. Chem. Soc. 2014, 136, 10202

[63] Wu, L.; Wang, F.; Wan, X.; Wang, D.; Chen, P.; Liu, G. J. Am. Chem. Soc. 2017, 139, 2904

[64] Ye, J. H.; Song, L.; Zhou, W. J.; Ju, T.; Yin, Z. B.; Yan, S. S.; Zhang, Z.; Li, J.; Yu, D. G. Angew. Chem., Int. Ed. 2016, 55, 10022.

[65] Zhou, S.; Song, T.; Chen, H.; Liu, Z.; Shen, H.; Li, C. Org. Lett. 2017, 19,698

[66] Fu, L.; Zhou, S.; Wan, X.; Chen, P.; Liu, G. J. Am. Chem. Soc. 2018, 140, 10965

[67] (a) Fadeyi, O. O.; Adamson, S. T.; Myles, E. L.; Okoro, C. O. Bioorg. Med. Chem. Lett. 2008, 18, 4172.

(b) Li, J.; Zhang, X.; Xiang, H.; Tong, L.; Feng, F.; Xie, H.; Ding, J.; Yang, C. J. Org. Chem. 2017, 82, 6795. (c) Apraku, J.; Okoro, C. O. Bioorg. Med. Chem. 2019, 27, 161

[68] Li, J. L.; Liu, Y. Q.; Zou, W. L.; Zeng, R.; Zhang, X.; Liu, Y.; Han, B.; He, Y.; Leng, H. J.; Li, Q. Z. Angew. Chem., Int. Ed. 2020, 59, 1863.

[69] (a) Park, C. M.; Jiang, Y. J. Chem. Sci. 2014, 5, 2347.

(b) Jana, S.; Clements, M. D.; Sharp, B. K.; Zheng, N. Org. Lett. 2010, $12,3736$.

(c) Qi, X. X.; Xu, X. X.; Park, C. M. Chem. Commun. 2012, 48, 3996.

[70] He, Y. T.; Wang, Q.; Zhao, J. H.; Liu, X. Y.; Xua, P. F.; Liang, Y. M. Chem. Commun. 2015, 51, 13209.

[71] (a) Ackermann, L.; Potukuchi, H. K. Org. Biomol. Chem. 2010, 8, 4503.

(b) Spiteri, C.; Moses, J. E. Angew. Chem., Int. Ed. 2010, 49, 31.

[72] Cheung, K. P. S.; Tsui, G. C. Org. Lett. 2017, 19, 2881.

[73] Zhu, A.; Xing, X. F.; Wang, S. L.; Yuan, D. H.; Zhu, G. M.; Geng, M. W.; Guo, Y. Y.; Zhang, G. S.; Li, L. J. Green Chem. 2019, 21, 3407.

[74] Chen, C.; Xie, Y.; Chu, L.; Wang, R. W.; Zhang, X.; Qing, F. L. Angew. Chem., Int. Ed. 2012, 51, 2492.

[75] Cheng, Y.; Muck-Lichtenfeld, C.; Studer, A. J. Am. Chem. Soc. 2018, $140,6221$.

[76] For reviews of radical additions to $\mathrm{C}=\mathrm{N}$ bonds:

(a) Miyabe, H. Synlett 2012, 23, 1709.

(b) Friestad, G. K. Tetrahedron 2001, 57, 5461.

(c) Friestad, G. K. Eur. J. Org. Chem. 2005, 2005, 3157.

(d) Friestad, G. K.; Mathies, A. K. Tetrahedron 2007, 63, 2541

(e) Yamada, K.; Tomioka, K. Chem. Rev. 2008, 108, 2874.
[77] Zheng, D. Q.; Studer, A. Org. Lett. 2019, 21, 325.

[78] Zhao, X.; Tu, H. Y.; Guo, L.; Zhu, S. Q.; Qing, F. L.; Chu, L. L. Nat. Commun. 2018, 9, 3488

[79] Tu, H. Y.; W, F.; Huo, L. P.; Li, Y. B.; Zhu, S. Q.; Zhao, X.; Li, H.; Qing, F. L.; Chu, L. L. J. Am. Chem. Soc. 2020, 142, 9604.

[80] Xiong, H.; Ramkumar, N.; Chiou, M. F.; Jian, W.; Li, Y.; Su, J. H.; Zhang, X.; Bao, H. Nat. Commun. 2019, 10, 1.

[81] Zhu, X. T.; Deng, W. L.; Chiou, M. F.; Ye, C. Q.; Jian, W. J.; Zeng, Y. H.; Jiao, Y. H.; Ge, L.; Li, Y. J.; Zhang, X. H.; Bao, H. L. J. Am. Chem. Soc. 2019, 141, 548

[82] Chu, X. Q.; Xie, Ting.; Li, Lin.; Ge, D. H.; Shen, Z. L.; Loh, T. P. Org. Lett. 2018, 20, 2749.

[83] (a) Davidson, B. S. Chem. Rev. 1993, 93, 1771.

(b) Jin, Z. Nat. Prod. Rep. 2006, 23, 464.

(c) Scott, J. D.; Williams, R. M. Chem. Rev. 2002, 102, 1669.

[84] (a) Wu, Y. C.; Liron, M.; Zhu, J. J. Am. Chem. Soc. 2008, 130, 7148 .

(b) Zhang, C.; Zink, D. L.; Ushio, M.; Burgess, B.; Onishi, R.; Masurekar, P.; Barrett, J. F.; Singh, S. B. Bioorg. Med. Chem. 2008, 16, 8818.

(c) Ii, K.; Ichikawa, S.; Al-Dabbagh, B.; Bouhss, A.; Matsuda, A. J. Med. Chem. 2010, 53, 3793.

(d) Andrade, S. F.; Teixeiraa, C. S.; Ramosb, J. P.; Lopesa, M. S.; Páduaa, R. M.; Oliveiraa, M. C.; Souza-Fagundes, E. M.; Alves, R. J. MedChem Comm 2014, 5, 1693.

(e) Andrade, S. F.; Oliveira, B. G.; Pereira, L. C.; Ramos, J. P.; Joaquim, A. R.; Steppe, M. E.; SouzaFagundes, M.; Alves, R. J. Eur. J. Med. Chem. 2017, 138, 13.

[85] Chu, X. Q.; Ge, D. H.; Wang, M. L.; Rao, W. D.; Loh, T. P.; Shen, Z. L. Adv. Synth. Catal. 2019, 361, 4082.

[86] For leading reviews, see:

(a) Prier, C. K.; Rankic, D. A.; MacMillan, D. W. C. Chem. Rev. 2013, 113, 5322 .

(b) Ravelli, D.; Protti, S.; Fagnoni, M. Chem. Rev. 2016, 116, 9850.

[87] For reviews, see:

(a) Paria, S.; Reiser, O. ChemCatChem 2014, 6, 2477.

(b) Reiser, O. Acc. Chem. Res. 2016, 49, 1990.

[88] Guo, Q. P.; Wang, M. R.; Wang, Y. F.; Xu, Z. Q.; Wang, R. Chem. Commun. 2017, 53, 12317

[89] Liu, H.; Guo, Q. P.; Chen, C.; Wang, M. R.; Xu, Z. Q. Org. Chem. Front. 2018, 5, 1522

[90] Guo, Q. P.; Wang, M. G.; Peng, Q.; Huo, Y. M.; Liu, Q.; Wang, R.; Xu, Z. Q. ACS Catal. 2019, 9, 4470.

[91] Li, Z.; Andrés, G. D.; Nevado, C. J. Am. Chem. Soc. 2015, 137, 11610

[92] Li, Z. D.; Merino, E.; Nevado, C. Top. Catal. 2017, 60, 545.

[93] Domański, S.; Chaładaj, W. ACS Catal. 2016, 6, 3452.

[94] Domanski, S.; Gatlik, B.; Chaladaj, W. Org. Lett. 2019, 21, 5021.

[95] Ni, C. F.; Zhu, L. G.; Hu, J. B. Acta Chim. Sinica 2015, 73, 90 (in Chinese). (倪传法, 朱林桂, 胡金波, 化学学报, 2015, 73, 90.)

[96] Wu, N. Y.; Xu, X. H.; Qing, F. L. ACS Catal. 2019, 9, 5726

[97] Zhang, C. W.; Li, Z. D.; Zhu, L.; Yu, L. M.; Wang, Z. T.; Li, C. Z. J. Am. Chem. Soc. 2013, 135, 14082.

[98] Peng, H. H.; Yuan, Z. L.; Wang, H. Y.; Guo, Y. L.; Liu, G. S. Chem. Sci. 2013, 4, 3172

[99] Yasu, Y.; Koike, T.; Akita, M. Org. Lett. 2013, 15, 2136.

[100] Liu, C. M.; Shi, E.; Xu, F.; Luo, Q.; Wang, H. X.; Chen, J. J.; Wan, X. B. Chem. Commun. 2015, 51, 1214

[101] Wang, Q.; He, Y. T.; Zhao, J. H.; Qiu, Y. F.; Zheng, L.; Hu, J. Y.; Yang, Y. C.; Liu, X. Y.; Liang, Y. M. Org. Lett. 2016, 18, 2664.

[102] Wang, Q.; Zheng, L.; He, Y. T.; Liang, Y. M. Chem. Commun. 2017, $53,2814$. 